EXPANSIÓN DE LAS UNIVERSIDADES E INSTITUTOS PROFESIONALES CUYA AUTONOMÍA HA SIDO CERTIFICADA POR EL CONSEJO SUPERIOR DE EDUCACIÓN

Cecilia Dooner* 



\section{EXPANSIÓN DE LAS UNIVERSIDADES E \\ INSTITUTOS PROFESIONALES CUYA AUTONOMÍA HA SIDO CERTIFICADA POR EL CONSEJO SUPERIOR DE EDUCACIÓN}

\section{Introducción}

Este estudio se enmarca en la línea de investigación que está desarrollando el Consejo Superior de Educación (CSE) a fin de aumentar y mejorar la información disponible acerca de la educación postsecundaria en el país. Es un estudio que busca analizar el crecimiento de un conjunto de instituciones y, particularmente, su comportamiento luego de que el CSE certificara su autonomía institucional.

Es de conocimiento general que, en las últimas décadas, ha habido un aumento significativo en la oferta educacional de nivel superior. Así, por ejemplo, de acuerdo a los datos registrados por el CSE, el número de programas de pregrado existentes en 1996 era de 1.325, mientras que en 2004 es de 4.062, es decir, se ha triplicado la cifra en ocho años.

Asimismo, un estudio de la Comisión Nacional de Acreditación de Pregrado (CNAP) revela que la oferta de sedes de instituciones de educación superior muestra un fuerte crecimiento desde 1980 hasta 2003, periodo en que se pueden distinguir tres momentos distintos:

- entre 1980 y 1990, hay un crecimiento producto del aumento del número de universidades, institutos profesionales y centros de formación técnica;

- entre 1990 y 2000 hay una detención y una leve disminución en el número de sedes, a raíz del cierre de algunas instituciones; 
- desde 2000 a 2003 hay un nuevo incremento en el número de sedes, que coincide con el aumento del sector de universidades privadas autónomas.

Se sugiere, entonces, una correlación entre la certificación de la autonomía institucional y el comportamiento de la oferta educacional.

No obstante, no se ha establecido hasta ahora si el aumento de la oferta educacional de estas instituciones, individualmente, ha sido constante en el tiempo o si muestra ciertos puntos de inflexión desde los cuales la oferta de programas académicos y sedes comienza a expandirse de manera inédita. Pues bien, la propuesta de este estudio es que la certificación de la autonomía institucional en los establecimientos que han pasado por el sistema de acreditación administrado por el CSE es un hito, a partir del cual ellos incrementan significativamente su oferta y sufren, como consecuencia, un crecimiento en los siguientes periodos académicos que supera de manera evidente su evolución histórica. Asimismo, se propone que esta expansión no siempre está acompañada de un aumento proporcional de ciertos elementos asociados a los recursos físicos y docentes involucrados en el proceso de enseñanza-aprendizaje.

El CSE cuenta con información relevante acerca de varios indicadores de desarrollo de las instituciones que han estado bajo su supervisión, las que constituyen una proporción importante de las universidades e institutos profesionales del sistema. En efecto, están en este grupo 24 de las 62 universidades actualmente en funcionamiento y 11 de los 45 institutos profesionales existentes. Se trata de las instituciones que han sido creadas al alero de la Ley Orgánica Constitucional de Enseñanza (LOCE), es decir, han iniciado sus actividades desde 1990 en adelante quedando directamente bajo la supervisión del Consejo; o bien, han sido creadas con anterioridad a ese año y han optado por la acreditación que realiza el CSE estando ya en funcionamiento. Sus periodos de acreditación dependen también de la LOCE, pues esta ley establece 
que el CSE verificará el desarrollo de los proyectos institucionales, comprobando el cumplimiento de cada proyecto por seis años y pudiendo prolongar la acreditación hasta por el plazo de cinco años adicionales. En otras palabras, las instituciones pueden estar bajo acreditación hasta once años desde su inicio de actividades. Una vez cumplido este lapso, el Consejo debe pronunciarse acerca de la capacidad de autonomía de las instituciones y determinar si es posible certificarla. En caso de otorgarse dicha certificación, la institución obtiene, por primera vez y para siempre, plena autonomía para otorgar títulos profesionales y grados académicos.

Al observar el número de certificaciones de autonomía que el CSE ha otorgado durante su funcionamiento la mayoría se ha concentrado fuertemente hacia fines de la década pasada y principios de la presente. En efecto, el 74\% de las certificaciones de autonomía fueron concedidas desde el año 1999 en adelante.

\section{Gráfico 1}

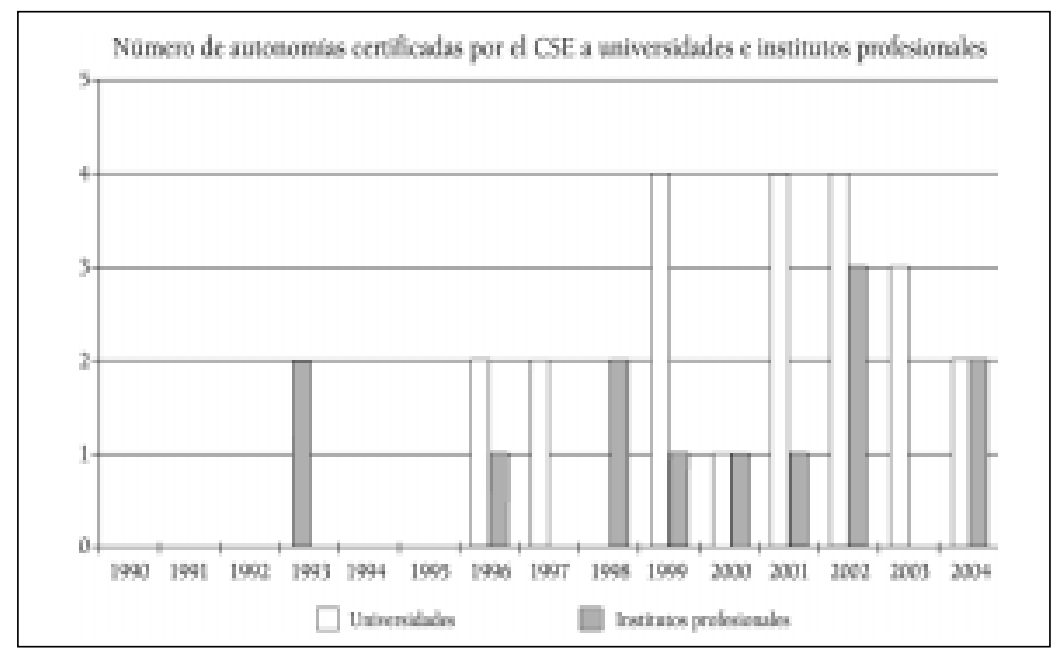

Fuente: Consejo Superior de Educación.

Esta distribución se explica, entonces, porque, dados los plazos de acreditación descritos, correspondió al CSE evaluar la capacidad de autonomía de muchas de estas instituciones a finales 
de esa década o a principios de la presente. Ello también explica que entre 1990 y 1995 no hubiera certificaciones de autonomía, con excepción de dos universidades que funcionaban con anterioridad a la promulgación de la LOCE y que optaron por el sistema de acreditación del Consejo.

Para efectos del sistema de educación superior esto significa que, en los últimos años, se han incorporado un conjunto importante de universidades e institutos profesionales que cuentan con plena autonomía para abrir nuevas sedes, carreras y vacantes. Esto configura un panorama diferente al de hace una década y levanta con más fuerza la pregunta por el comportamiento de la oferta educacional a partir de la condición de autonomía.

\section{La expansión de las instituciones a partir de la autonomía}

Las instituciones que se analizan en este estudio corresponden a las 24 universidades y los 11 institutos profesionales que han obtenido la certificación de su autonomía institucional a través del CSE. Ellas han obtenido la certificación de su autonomía entre los años 1993 y 2004.

Para analizar la evolución de estas instituciones se utilizarán básicamente cinco indicadores correspondientes a características de las instituciones que reflejan su crecimiento o decrecimiento en el tiempo: la matrícula total y de primer año, la cantidad de carreras, el número de sedes y de áreas del conocimiento que las instituciones desarrollan.

\section{La matrícula de las instituciones}

En términos generales, el comportamiento de la matrícula de las instituciones cuya autonomía ha sido certificada por el Consejo ha sido ascendente entre 1996 y 2004. 
Gráfico 2

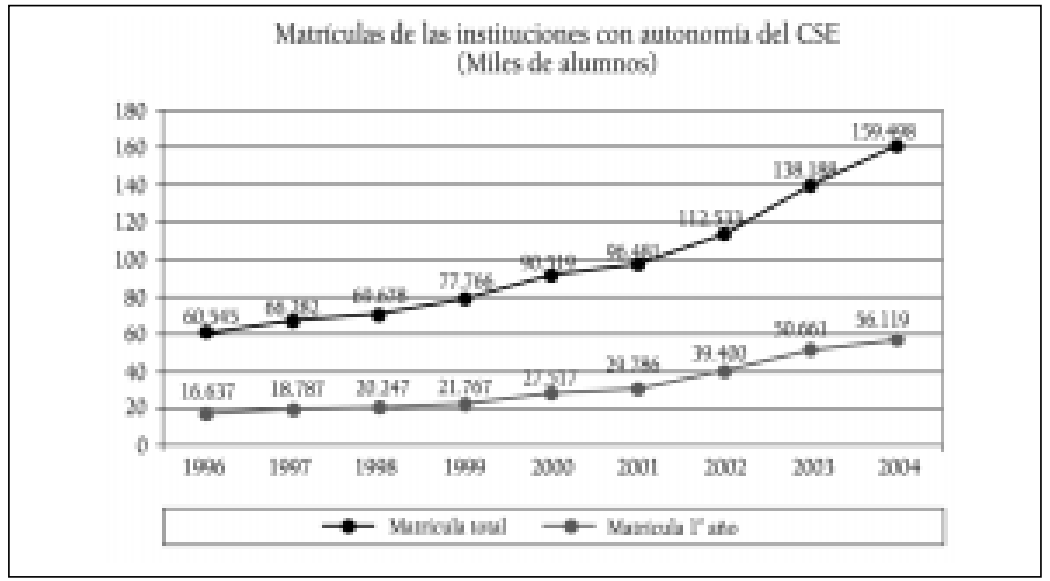

Fuente: Consejo Superior de Educación ${ }^{1}$.

Aun cuando no es posible identificar puntos de inflexión muy notorios, se observan cambios a principios de esta década. En efecto, la matrícula nueva alcanzó en 2000, 2002 y 2003 variaciones de 26, 32 y $29 \%$ respectivamente, lo que se traduce en que, a partir de 2002 , el aumento de matrícula es más drástico de año en año, alcanzando un incremento anual cercano a los diez mil alumnos, en circunstancias que a principios del periodo las diferencias anuales eran de alrededor de dos mil alumnos. Esto quiere decir que desde 2002 parece inaugurarse una nueva tendencia de crecimiento más acelerado de la matrícula de primer año. Para tener un referente, la variación anual de la matrícula de primer año de todas las universidades e institutos profesionales en el país, de acuerdo a datos de INDICES $2005^{2}$, alcanza

1 De las 35 instituciones acreditadas por el Consejo con la autonomía institucional, seis fueron eliminadas para la construcción de este gráfico. Éstas no habían entregado datos en algunos años o contenían algunos erróneos. No obstante, cabe señalar que, a excepción de dos de las instituciones excluidas, todas las demás mostraron una tendencia de crecimiento de su matrícula.

2 INDICES es una publicación del CSE que informa sobre instituciones de educación superior, carreras y programas de pregrado, y posgrado (maestrías, doctorados, especialidades médicas y odontológicas), e identifica los programas acreditados por la Comisión Nacional de Acreditación de Pregrado (CNAP) y la Comisión Nacional de Acreditación de Postgrado (CONAP), respectivamente. También entrega datos acerca de las carreras y programas impartidos por las escuelas y academias del Ejército, la Armada, la Fuerza Aérea, Carabineros y la Policía de Investigaciones. 
en 2003 un 10\% y en 2004 un 4\%. Es decir, la elevada tasa de crecimiento en estos últimos años parece ser una característica propia de las instituciones más jóvenes.

Asimismo, la matrícula total de estas instituciones muestra un aumento sistemático en el periodo y la variación anual también se incrementa en la mayoría de los años, elevándose particularmente desde 2002 (17\% de variación respecto del año anterior) y luego en 2003 (23\% de variación). Al igual que en la matrícula de primer año, se aprecia a principios de esta década un cambio en la tendencia de la tasa de crecimiento, de modo que, hacia finales del periodo, el incremento anual supera los 20 mil alumnos. En este indicador -el de matrícula total- las cifras de crecimiento anual de universidades e institutos profesionales de todo el sistema de educación superior son nuevamente bastante más bajas. En 2003 la variación llega a 8\% y en 2004 a $7 \%$.

La siguiente tabla muestra las cifras de matrícula y su variación anual en tres años de su desarrollo: el año previo a la autonomía, es decir, cuando la institución se encuentra aún en acreditación con el CSE; el año en que se certifica la autonomía, vale decir, la institución llega al fin de su acreditación y obtiene la certificación de su autonomía en algún momento del año; y el año posterior a la autonomía, es decir, la institución ya no está sujeta a la acreditación con el Consejo.

Se excluyeron de este análisis las instituciones que obtuvieron su autonomía antes de 1997 y después de 2003, pues en esos casos no hay datos disponibles para la comparación en los tres años. Además, se indican con un asterisco las instituciones que obtuvieron la certificación de su autonomía en el mes de enero, lo que explica que, en algunos casos, el cambio en la tasa de crecimiento se produzca el mismo año de su autonomía. 
Tabla 1: Matrícula de primer año y total. Antes y después de la autonomía.

\begin{tabular}{|c|c|c|c|c|c|}
\hline \multicolumn{2}{|l|}{ Institución / Año autonomía } & $\begin{array}{l}\text { Año anterior } \\
\text { autonomía }\end{array}$ & $\begin{array}{c}\text { Año } \\
\text { autonomía }\end{array}$ & \multicolumn{2}{|c|}{$\begin{array}{l}\text { Año posterior } \\
\text { autonomía }\end{array}$} \\
\hline \\
\hline \multirow[t]{2}{*}{ AIEP / 2002* } & $1^{\text {er año }}$ & $132(-14 \%)$ & $138 \quad(5 \%)$ & 2.901 & (2002\%) \\
\hline & Total & $372(-31 \%)$ & $411(10 \%)$ & 3.263 & $(694 \%)$ \\
\hline \multirow[t]{2}{*}{ Diego Portales / 2001} & $1^{\text {er año }}$ & $582(38 \%)$ & $711(22 \%)$ & 3.367 & $(374 \%)$ \\
\hline & Total & $1.914(10 \%)$ & $1.974(3 \%)$ & 4.767 & $(141 \%)$ \\
\hline \multirow[t]{2}{*}{ EATRI / 2002} & $1^{\text {er }}$ año & $44(-25 \%)$ & $74(68 \%)$ & 62 & $(-16 \%)$ \\
\hline & Total & $185 \quad(3 \%)$ & $176(-5 \%)$ & 179 & $(2 \%)$ \\
\hline \multirow[t]{2}{*}{ La Araucana / 1998} & $1^{\text {er }}$ año & 709 (14\%) & $982(39 \%)$ & 1.085 & $(10 \%)$ \\
\hline & Total & $1.783(11 \%)$ & $2.251(26 \%)$ & 2.605 & $(16 \%)$ \\
\hline \multirow[t]{2}{*}{ Santo Tomás / 2000} & $1^{\text {er }}$ año & $560 \quad(-4 \%)$ & $614(10 \%)$ & 678 & $(10 \%)$ \\
\hline & Total & 2.029 & $2.044 \quad(1 \%)$ & 1.972 & $(-4 \%)$ \\
\hline \multicolumn{6}{|l|}{ UNIVERSIDADES } \\
\hline \multirow{2}{*}{$\begin{array}{l}\text { Academia de } \\
\text { Humanismo Cristiano / } 1999\end{array}$} & $1^{\text {er }}$ año & $(-8 \%)$ & $661(17 \%)$ & 898 & $(36 \%)$ \\
\hline & Total & $1.807 \quad(1 \%)$ & $1.958 \quad(8 \%)$ & 2.328 & $(19 \%)$ \\
\hline \multirow[t]{2}{*}{ Andrés Bello / 1999} & $1^{\text {er }}$ año & $1.559(-14 \%)$ & $1.420(-9 \%)$ & 3.247 & $(129 \%)$ \\
\hline & Total & $6.312 \quad(0 \%)$ & $6.529 \quad(3 \%)$ & 10.807 & $(66 \%)$ \\
\hline \multirow[t]{2}{*}{ Autónoma del Sur / 2002} & $1^{\text {er }}$ año & $581(-14 \%)$ & $635(9 \%)$ & 1.747 & $(175 \%)$ \\
\hline & Total & $2.126 \quad(-4 \%)$ & $2.307 \quad(9 \%)$ & 5.892 & $(155 \%)$ \\
\hline \multirow[t]{2}{*}{ Católica Silva Henríquez / 2003* } & $1^{\text {er }}$ año & $991 \quad(5 \%)$ & $1.058 \quad(7 \%)$ & 1.091 & $(3 \%)$ \\
\hline & Total & $4.164 \quad(-1 \%)$ & $4.124(-1 \%)$ & 4.352 & $(6 \%)$ \\
\hline \multirow{2}{*}{$\begin{array}{l}\text { De Arte y Ciencias Sociales } \\
\text { ARCIS / } 1999\end{array}$} & $1^{\text {er }}$ año & $831 \quad(33 \%)$ & $796(-4 \%)$ & 909 & $(14 \%)$ \\
\hline & Total & $2.546(13 \%)$ & $2.637(4 \%)$ & 2.862 & $(9 \%)$ \\
\hline \multirow{2}{*}{$\begin{array}{l}\text { De Artes, Ciencias y } \\
\text { Comunicación UNIACC/ } 1999\end{array}$} & $1^{\text {er }}$ año & $285(40 \%)$ & $190(-33 \%)$ & 451 & $(137 \%)$ \\
\hline & Total & $910 \quad(12 \%)$ & $931 \quad(2 \%)$ & 1.150 & $(24 \%)$ \\
\hline \multirow[t]{2}{*}{ De Ciencias de la Informática/ 2003* } & $1^{\text {er }}$ año & $748(-14 \%)$ & $1.122(50 \%)$ & 1.118 & $(0 \%)$ \\
\hline & Total & $2.351(-15 \%)$ & $3.312(41 \%)$ & 3.404 & $(3 \%)$ \\
\hline \multirow[t]{2}{*}{ De Las Américas / 1997} & $1^{\text {er }}$ año & $366 \quad(s / i)$ & $613(67 \%)$ & 829 & $(35 \%)$ \\
\hline & Total & 1.309 & $1.558(19 \%)$ & 1.888 & $(21 \%)$ \\
\hline \multirow[t]{2}{*}{ De Viña del Mar / 2000} & $1^{\text {er }}$ año & $(3 \%)$ & $826(12 \%)$ & 925 & $(12 \%)$ \\
\hline & Total & 2.883 & $3.072(7 \%)$ & 3.236 & $(5 \%)$ \\
\hline \multirow[t]{2}{*}{ Del Desarrollo / 1997* } & $1^{\text {er }}$ año & 527 & $629(19 \%)$ & 670 & $(7 \%)$ \\
\hline & Total & $1.438 \quad(\mathrm{~s} / \mathrm{i})$ & $1.800(25 \%)$ & 2.028 & $(13 \%)$ \\
\hline \multirow[t]{2}{*}{ Del Mar / 2002* } & $1^{\text {er }}$ año & $932(-12 \%)$ & $1.275(37 \%)$ & 5.386 & $(322 \%)$ \\
\hline & Total & $3.591 \quad(0 \%)$ & $3.957(10 \%)$ & 8.388 & $(112 \%)$ \\
\hline \multirow[t]{2}{*}{ Internacional Sek / 2002} & $1^{\text {er }}$ año & $175 \quad(-5 \%)$ & $169(-3 \%)$ & 240 & $(42 \%)$ \\
\hline & Total & $690 \quad(2 \%)$ & $703 \quad(2 \%)$ & 710 & $(1 \%)$ \\
\hline \multirow[t]{2}{*}{ La República / 2001* } & $1^{\text {er }}$ año & $593(-28 \%)$ & $688(16 \%)$ & 1.012 & $(47 \%)$ \\
\hline & Total & $2.565 \quad(-1 \%)$ & $2.810(10 \%)$ & 3.295 & $(17 \%)$ \\
\hline \multirow[t]{2}{*}{ Mariano Egaña / 2001} & $1^{\text {er }}$ año & $111(640 \%)$ & $98(-12 \%)$ & 651 & $(564 \%)$ \\
\hline & Total & $381 \quad(2 \%)$ & $339(-11 \%)$ & 905 & $(167 \%)$ \\
\hline
\end{tabular}




\begin{tabular}{llrrrrrr} 
San Sebastián / 2001 & $1^{\text {er año }}$ & 529 & $(2 \%)$ & $726(37 \%)$ & 1.792 & $(147 \%)$ \\
& Total & 2.139 & $(6 \%)$ & 2.650 & $(24 \%)$ & 3.827 & $(44 \%)$ \\
Santo Tomás / 2003* & $1^{\text {er año }}$ & 1.295 & $(23 \%)$ & 1.409 & $(9 \%)$ & 4.587 & $(226 \%)$ \\
& Total & 4.944 & $(0 \%)$ & 4.885 & $(-1 \%)$ & 8.427 & $(73 \%)$ \\
Pérez Rosales / 2001 & $1^{\text {er año }}$ & 435 & $(13 \%)$ & $375(-14 \%)$ & 372 & $(-1 \%)$ \\
& Total & 1.231 & $(11 \%)$ & 1.280 & $(4 \%)$ & 1.243 & $(-3 \%)$ \\
\hline
\end{tabular}

Como dato grueso, lo primero que llama la atención es que sólo tres de estas instituciones muestran una variación negativa en el año siguiente a la certificación de su autonomía y se trata solamente de descensos leves. De las instituciones restantes, todas presentan evoluciones positivas y a lo menos doce muestran un incremento de matrícula muy superior al año anterior o dos años anteriores (cifras destacadas con negrita), lo que se manifiesta, en la mayoría de los casos, tanto en la matrícula de primer año como en la matrícula total. Entre ellas, seis instituciones superan el $100 \%$ de crecimiento anual en ambos indicadores, e incluso una de ellas, el Instituto Profesional AIEP, muestra un aumento de su matrícula nueva que supera el $2.000 \%$ de variación al año siguiente de su autonomía. A excepción de la Universidad de las Américas, todas estas instituciones obtuvieron su autonomía desde 1999 en adelante, lo que explica, en una medida importante, la evolución general de la matrícula observada en el gráfico 2, donde el aumento más significativo se aprecia a principios de esta década.

Sin embargo, los datos de la tabla anterior no consideran aún el comportamiento histórico de las instituciones, por lo que se examinará la situación de estos 12 casos que muestran cambios significativos en el aumento de su matrícula, con relación al promedio de la variación anual de matrícula total y de primer año desde 1996 hasta un año antes de su autonomía.

Tabla 2: Variación anual de matrícula nueva y total. Antes y después de la autonomía.

\begin{tabular}{llccc}
\hline Institución / Año autonomía & & $\begin{array}{c}\text { Promedio } \\
\text { variación }\end{array}$ & $\begin{array}{c}\text { Variación } \\
\text { año autonomía }\end{array}$ & $\begin{array}{c}\text { Variación año } \\
\text { posterior } \\
\text { autonomía }\end{array}$ \\
\hline INSTITUTOS PROFESIONALES & & & & \\
\hline AIEP / 2002* & Nueva & $1 \%$ & $5 \%$ & $2.002 \%$ \\
& Total & $-7 \%$ & $10 \%$ & $694 \%$ \\
Diego Portales / 2001 & Nueva & $7 \%$ & $22 \%$ & $374 \%$ \\
& Total & $4 \%$ & $3 \%$ & $141 \%$ \\
\hline UNIVERSIDADES & & & & \\
\hline Andrés Bello / 1999 & Nueva & $0 \%$ & $-9 \%$ & $129 \%$ \\
& Total & $0 \%$ & $3 \%$ & $66 \%$ \\
Autónoma del Sur / 2002 & Nueva & $9 \%$ & $9 \%$ & $175 \%$ \\
& Total & $21,4 \%$ & $9 \%$ & $155 \%$ \\
De Artes, Ciencias y & Nueva & $4,5 \%$ & $-33 \%$ & $137 \%$ \\
Comunicación UNIACC/ 1999 & Total & $10 \%$ & $2 \%$ & $24 \%$ \\
De Ciencias de & Nueva & $14,6 \%$ & $50 \%$ & $0 \%$ \\
la Informática / 2003* & Total & $11,5 \%$ & $41 \%$ & $3 \%$
\end{tabular}




\begin{tabular}{llrrr} 
Del Mar / 2002* & Nueva & $5 \%$ & $37 \%$ & $322 \%$ \\
& Total & $8,4 \%$ & $10 \%$ & $112 \%$ \\
Internacional Sek / 2002 & Nueva & $-1 \%$ & $-3 \%$ & $42 \%$ \\
& Total & $0,4 \%$ & $2 \%$ & $1 \%$ \\
La República / 2001* & Nueva & $6,5 \%$ & $16 \%$ & $47 \%$ \\
& Total & $6 \%$ & $10 \%$ & $17 \%$ \\
Mariano Egaña / 2001 & Nueva & $136 \%$ & $-12 \%$ & $564 \%$ \\
& Total & $-5 \%$ & $-11 \%$ & $167 \%$ \\
San Sebastián / 2001 & Nueva & $8,5 \%$ & $37 \%$ & $147 \%$ \\
& Total & $7 \%$ & $24 \%$ & $44 \%$ \\
Santo Tomás / 2003* & Nueva & $7 \%$ & $9 \%$ & $226 \%$ \\
& Total & $7 \%$ & $-1 \%$ & $73 \%$ \\
\hline
\end{tabular}

* Estas instituciones obtuvieron la certificación de su autonomía en el mes de enero, lo que explica que, en algunos casos, el cambio en la tasa de crecimiento ocurra en el mismo año de la autonomía.

Al comparar el comportamiento post-autonomía con una variable predominantemente de tendencia, como es el promedio de variación anual pre-autonomía de las instituciones, el diagnóstico no cambia significativamente. En efecto, incorporar el promedio muestra que algunas instituciones tuvieron, entre 1996 y el año previo a obtener la autonomía, una tendencia de crecimiento mayor que la que presenta el año anterior a la autonomía, como ocurre con el Instituto Profesional AIEP, la Universidad Autónoma del Sur, la Universidad de Ciencias de la Informática y la Universidad La República. Otras muestran un incremento histórico inferior al del último año anterior a la autonomía; tal es el caso de la Universidad Diego Portales, la Universidad de Artes, Ciencias y Comunicación UNIACC, la Universidad Mariano Egaña y la Universidad Santo Tomás. No obstante esas variaciones, en todas estas instituciones el aumento de matrícula en el año de la autonomía o en el año posterior a ella es muy superior a la variación promedio. Ello indica que el quiebre en la tasa de crecimiento no es sólo respecto del año anterior a la autonomía sino respecto de un periodo de tiempo mayor.

Sin embargo, los puntos de inflexión de este grupo de doce instituciones no es lo único que explica el quiebre en el comportamiento global de la matrícula observado en el gráfico 2. 
Se debe considerar aquí otro factor, a saber, la incidencia de instituciones que experimentan un aumento considerable de su matrícula a principios de esta década, aun cuando su autonomía fue certificada anteriormente. Así, por ejemplo, el I. P. Santo Tomás presenta variaciones de matrícula elevadas ( $97 \%$ en matrícula nueva y $68 \%$ en matrícula total) en 2002, dos años después de su autonomía, y posteriormente, en el año 2004, tiene una variación de $73 \%$ en su matrícula nueva, superando con creces su variación promedio de matrícula de primer año que es de 32\% entre 1997 y 2003. Del mismo modo, la Universidad Andrés Bello, que obtuvo su autonomía en 1999, muestra variaciones de matrícula por encima de lo habitual en 2002, año en que logra cifras cercanas al 25\% de crecimiento, que son superadas sólo por las que había obtenido en 2000, un año después de obtener su autonomía. Otro caso es el de la Universidad ARCIS, que en el año 2001, dos años después de su autonomía, presenta variaciones de $79 \%$ en su matrícula nueva y de $48 \%$ en la matrícula total. La Universidad Diego Portales, a su vez, muestra en 2002 el mayor incremento de matrícula nueva del periodo, alcanzando un $25 \%$ de crecimiento. La Universidad Finis Terrae, que obtuvo su autonomía en 1996, tiene en 2002 un aumento de matrícula nueva que se traduce en una variación de $42 \%$, distanciándose de las cifras de otros años.

De este modo, además de la expansión de la matrícula de las instituciones tras la certificación de su autonomía y de la concentración de las certificaciones a principios de esta década, hay un conjunto de instituciones cuya autonomía no es reciente, que con crecimientos anuales algo más elevados en los últimos años que sus promedios, agudizan la tendencia agregada de quiebre en la tasa de crecimiento.

\section{El número de sedes y carreras abiertas por las instituciones}

Las sedes y carreras que una institución crea son una consecuencia directa de la gestión institucional y de una opción estratégica de desarrollo. Aun cuando suele asociarse a antecedentes de matrícula 
y a otras variables relativas a la regulación externa de mercado, su implementación depende, en definitiva, de una decisión institucional. A continuación se examina la evolución de sedes y programas de pregrado ofrecidos por las instituciones cuya autonomía ha sido certificada por el CSE.

Es relevante considerar que mientras las instituciones se encuentran en proceso de acreditación con el CSE requieren someter a consideración de este organismo los proyectos de nuevas sedes o carreras y requieren obtener la aprobación del Consejo para poder implementarlos. Una vez que se ha certificado su autonomía, no necesitan de una aprobación externa para adoptar ese tipo de decisiones.

Para contabilizar la cantidad de sedes abiertas por una institución, se considera como sede al inmueble, conjunto de inmuebles, conjunto de centros académicos o campus con que cuenta la institución en una determinada ciudad, distinta de aquella o aquellas en que la institución tiene su casa central o sus otras sedes oficialmente reconocidas. De ese modo, dos o más inmuebles en una misma ciudad corresponden a una misma sede.

Con esta definición, se obtiene una evolución del número de sedes que confirma las tendencias ascendentes observadas en la matrícula. 
Gráfico 3

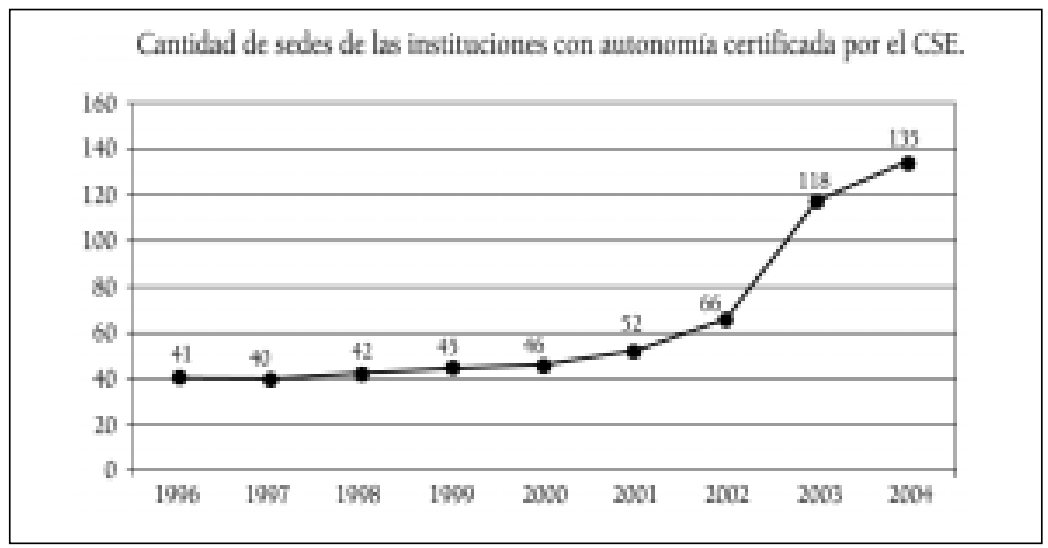

Fuente: Consejo Superior de Educación ${ }^{3}$.

Se hace más evidente la expansión de la oferta educativa en los últimos años, pues, además de mostrar un aumento de sedes en todo el periodo, en 2002 éstas se incrementan en más de 10 y luego, en 2003, aumentan desde 66 a 118, prácticamente duplicando su número de un año al siguiente. En la apertura de nuevas sedes se aprecia claramente un punto de inflexión en el año 2003.

Esta tendencia coincide con el comportamiento que se observa en materia de apertura de sedes en todo Chile. En efecto, de acuerdo a datos entregados por la CNAP y por el Ministerio de Educación, la cantidad de sedes de las universidades e institutos profesionales del sistema ha pasado de 216 en 1996 a 342 en 2004. Asimismo, se aprecia un crecimiento sostenido en los últimos años que se traduce en variaciones anuales del número de sedes de 15 , 17 y 22\% en los años 2002, 2003 y 2004 respectivamente.

Las carreras, por su parte, se contabilizan considerando como carreras distintas todos los programas académicos de pregrado que,

3 De las 35 instituciones acreditadas por el Consejo, una fue eliminada para la construcción de este gráfico, ya que no entregó datos en algunos años del periodo considerado. 
aun siendo curricularmente idénticos, sean dictados en jornadas distintas o en sedes diferentes.

Tomando en cuenta lo anterior, la cantidad de carreras ofrecidas por estas instituciones ha mostrado un incremento sostenido en todo el periodo, que se agudiza desde el año 2000 y que muestra la mayor alza en 2003. Esta tendencia coincide con aquella observada en la evolución del número de sedes, lo cual resulta razonable dado que la apertura de nuevas sedes conlleva la apertura de nuevos programas académicos.

Gráfico 4

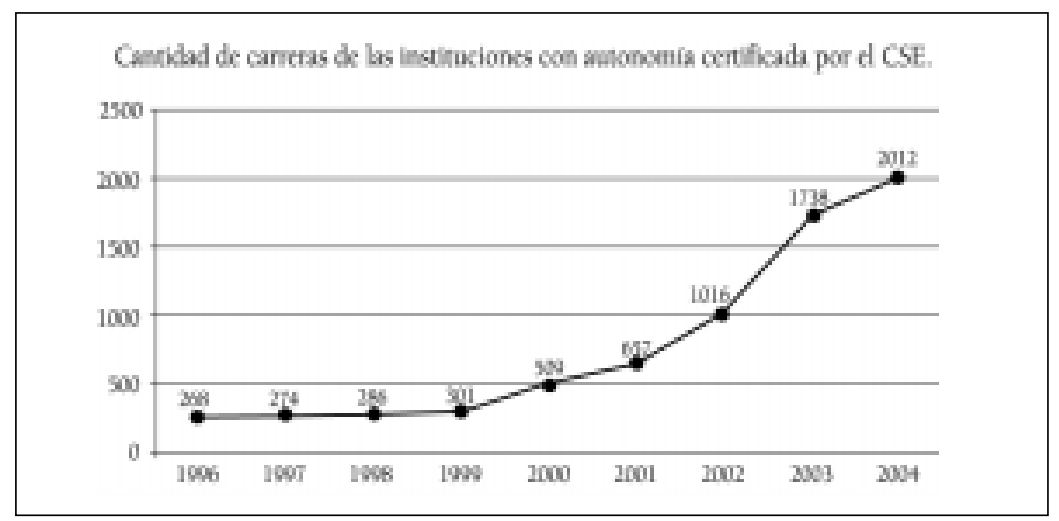

Fuente: Consejo Superior de Educación ${ }^{4}$.

Una cifra elocuente que ratifica este comportamiento es que el promedio del número de programas de pregrado ofrecidos por estas instituciones ha pasado desde 8,1 carreras en 1996 a 59,2 en 2004.

A continuación se revisa el comportamiento del número de carreras y sedes antes y después de la autonomía de las instituciones. Se excluyen también de este análisis las instituciones que obtuvieron su autonomía antes de 1997 y después de 2003, ya que ellas no cuentan con datos para la comparación en los tres años.

4 De las 35 instituciones acreditadas por el Consejo, una fue eliminada para la construcción de este gráfico, ya que no entregó datos en algunos años del periodo considerado. 
Tabla 3: Variación anual de sedes y carreras. Antes y después de la autonomía.

\begin{tabular}{|c|c|c|c|c|}
\hline Institución / Año autonomía & & $\begin{array}{c}\text { Año anterior } \\
\text { autonomía }\end{array}$ & Año autonomía & $\begin{array}{l}\text { Año posterior } \\
\text { autonomía }\end{array}$ \\
\hline INSTITUTOS PROFESIONALES & & & & \\
\hline AIEP / 2002* & Sedes & $2 \quad(0 \%)$ & $(0 \%)$ & $7 \quad(250 \%)$ \\
\hline & Carreras & $3(-57 \%)$ & $(0 \%)$ & $125(4067 \%)$ \\
\hline De Artes y & Sedes & $1 \quad(0 \%)$ & $(0 \%)$ & $1 \quad(0 \%)$ \\
\hline Comunicación ARCOS / 1999 & Carreras & $(0 \%)$ & $(0 \%)$ & $(100 \%)$ \\
\hline Diego Portales / 2001 & Sedes & $1 \quad(0 \%)$ & $(0 \%)$ & $(300 \%)$ \\
\hline & Carreras & $7(-22 \%)$ & $11 \quad(57 \%)$ & $(491 \%)$ \\
\hline EATRI / 2002 & Sedes & $1 \quad(0 \%)$ & $1 \quad(0 \%)$ & $(0 \%)$ \\
\hline & Carreras & $(0 \%)$ & $(0 \%)$ & $(71 \%)$ \\
\hline ESUCOMEX / 2002* & Sedes & $(0 \%)$ & $(0 \%)$ & $(0 \%)$ \\
\hline & Carreras & $(0 \%)$ & $(0 \%)$ & $(33 \%)$ \\
\hline La Araucana / 1998 & Sedes & $(0 \%)$ & $2(100 \%)$ & $(0 \%)$ \\
\hline & Carreras & $(0 \%)$ & $6(20 \%)$ & $(0 \%)$ \\
\hline Santo Tomás / 2000 & Sedes & $(0 \%)$ & $6 \quad(0 \%)$ & $(-17 \%)$ \\
\hline & Carreras & $(0 \%)$ & $22(175 \%)$ & $(118 \%)$ \\
\hline UNIVERSIDADES & & & & \\
\hline Academia de & Sedes & $(0 \%)$ & $(0 \%)$ & $(0 \%)$ \\
\hline Humanismo Cristiano / 1999 & Carreras & $(0 \%)$ & $(0 \%)$ & $(17 \%)$ \\
\hline Andrés Bello / 1999 & Sedes & $(0 \%)$ & $(0 \%)$ & $(100 \%)$ \\
\hline & Carreras & $16(23 \%)$ & $(0 \%)$ & $(156 \%)$ \\
\hline Autónoma del Sur / 2002 & Sedes & $1 \quad(0 \%)$ & $(0 \%)$ & $(200 \%)$ \\
\hline & Carreras & $10 \quad(43 \%)$ & $12(20 \%)$ & $(300 \%)$ \\
\hline Bolivariana / 2002* & Sedes & $1 \quad(0 \%)$ & $3(200 \%)$ & $(0 \%)$ \\
\hline & Carreras & $7(-13 \%)$ & $25(257 \%)$ & $(-4 \%)$ \\
\hline Católica Silva Henríquez / 2003* & Sedes & $1 \quad(0 \%)$ & $1 \quad(0 \%)$ & $(0 \%)$ \\
\hline & Carreras & $28 \quad(-3 \%)$ & $24(-14 \%)$ & $(-29 \%)$ \\
\hline De Arte y Ciencias Sociales & Sedes & $1 \quad(0 \%)$ & $1 \quad(0 \%)$ & $(0 \%)$ \\
\hline ARCIS / 1999 & Carreras & $(0 \%)$ & $(0 \%)$ & $(38 \%)$ \\
\hline De Artes, Ciencias y & Sedes & $1 \quad(0 \%)$ & $(0 \%)$ & $(0 \%)$ \\
\hline Comunicación UNIACC/ 1999 & Carreras & $11(10 \%)$ & $(9 \%)$ & $(-17 \%)$ \\
\hline De Ciencias de & Sedes & $1 \quad(0 \%)$ & $(0 \%)$ & $(0 \%)$ \\
\hline la Informática / 2003* & Carreras & $14(-13 \%)$ & $(86 \%)$ & $(23 \%)$ \\
\hline De Las Américas / 1997 & Sedes & $1 \quad(\mathrm{~s} / \mathrm{i})$ & $(0 \%)$ & $(0 \%)$ \\
\hline & Carreras & $(\mathrm{s} / \mathrm{i})$ & $(0 \%)$ & $(0 \%)$ \\
\hline De Viña del Mar / 2000 & Sedes & $(0 \%)$ & $(0 \%)$ & $(0 \%)$ \\
\hline & Carreras & $(0 \%)$ & $(0 \%)$ & $(59 \%)$ \\
\hline Del Desarrollo / 1997* & Sedes & $(\mathrm{s} / \mathrm{i})$ & $1 \quad(0 \%)$ & $(0 \%)$ \\
\hline & Carreras & $(\mathrm{s} / \mathrm{i})$ & $7(-13 \%)$ & $(14 \%)$ \\
\hline Del Mar / 2002* & Sedes & $(0 \%)$ & $1 \quad(0 \%)$ & $(900 \%)$ \\
\hline & Carreras & $27 \quad(23 \%)$ & $104(285 \%)$ & $(137 \%)$ \\
\hline Internacional Sek / 2002 & Sedes & $1 \quad(0 \%)$ & $1 \quad(0 \%)$ & $(0 \%)$ \\
\hline & Carreras & $(0 \%)$ & $(0 \%)$ & $(83 \%)$ \\
\hline La República / 2001* & Sedes & $1 \quad(0 \%)$ & $1 \quad(0 \%)$ & $(100 \%)$ \\
\hline & Carreras & $13(18 \%)$ & $10(-23 \%)$ & $(160 \%)$ \\
\hline
\end{tabular}




\begin{tabular}{llrrrrrr} 
Mariano Egaña / 2001 & Sedes & 1 & $(0 \%)$ & 1 & $(0 \%)$ & 1 & $(0 \%)$ \\
& Carreras & 5 & $(150 \%)$ & 3 & $(-40 \%)$ & 8 & $(167 \%)$ \\
San Sebastián / 2001 & Sedes & 1 & $(0 \%)$ & 1 & $(0 \%)$ & 2 & $(0 \%)$ \\
& Carreras & 10 & $(0 \%)$ & 13 & $(30 \%)$ & 28 & $(115 \%)$ \\
Santo Tomás / 2003* & Sedes & 1 & $(0 \%)$ & $11(1000 \%)$ & 12 & $(9 \%)$ \\
& Carreras & 18 & $(0 \%)$ & 110 & $(511 \%)$ & 127 & $(15 \%)$ \\
Pérez Rosales / 2001 & Sedes & 1 & $(0 \%)$ & 1 & $(0 \%)$ & 1 & $(0 \%)$ \\
& Carreras & 7 & $(17 \%)$ & 8 & $(14 \%)$ & 26 & $(225 \%)$ \\
\hline
\end{tabular}

*En esta tabla se observa que 17 instituciones muestran un cambio significativo en su crecimiento de sedes, de carreras o de ambas. Es útil ratificar aquello con el cálculo del promedio de la variación anual en los años anteriores a la autonomía, con el fin de evitar posibles distorsiones provocadas por situaciones excepcionales en el año anterior a ella.

Tabla 4: Variación anual de sedes y carreras. Antes y después de la autonomía.

\begin{tabular}{llrrrrr}
\hline Institución / Año autonomía & & $\begin{array}{c}\text { Promedio } \\
\text { variación }\end{array}$ & $\begin{array}{r}\text { Variación año } \\
\text { autonomía }\end{array}$ & $\begin{array}{c}\text { Variación año } \\
\text { posterior } \\
\text { autonomía }\end{array}$ \\
\hline INSTITUTOS PROFESIONALES & & & & & & \\
\hline AIEP / 2002* & Sedes & $0 \%$ & 2 & $(0 \%)$ & 7 & $(250 \%)$ \\
& Carreras & $-3,4 \%$ & 3 & $(0 \%)$ & 125 & $(4067 \%)$ \\
De Artes y Comunicación & Sedes & $0 \%$ & 1 & $(0 \%)$ & 1 & $(0 \%)$ \\
ARCOS / 1999 & Carreras & $0 \%$ & 4 & $(0 \%)$ & 8 & $(100 \%)$ \\
Diego Portales / 2001 & Sedes & $0 \%$ & 1 & $(0 \%)$ & 4 & $(300 \%)$ \\
& Carreras & $-5,5 \%$ & 11 & $(57 \%)$ & 65 & $(491 \%)$ \\
EATRI / 2002 & Sedes & $0 \%$ & 1 & $(0 \%)$ & 1 & $(0 \%)$ \\
& Carreras & $70 \%$ & 7 & $(0 \%)$ & 12 & $(71 \%)$ \\
Santo Tomás / 2000 & Sedes & $-4,6 \%$ & 6 & $(0 \%)$ & 5 & $(-17 \%)$ \\
& Carreras & $0 \%$ & 22 & $(175 \%)$ & 48 & $(118 \%)$ \\
\hline UNIVERSIDADES & & & & & & \\
\hline Andrés Bello / 1999 & Sedes & $0 \%$ & 1 & $(0 \%)$ & 2 & $(100 \%)$ \\
Autónoma del Sur / 2002 & Carreras & $15,5 \%$ & 16 & $(0 \%)$ & 41 & $(156 \%)$ \\
& Sedes & $0 \%$ & 1 & $(0 \%)$ & 3 & $(200 \%)$ \\
Bolivariana / 2002* & Carreras & $16,6 \%$ & 12 & $(20 \%)$ & 48 & $(300 \%)$ \\
& Sedes & $0 \%$ & 3 & $(200 \%)$ & 3 & $(0 \%)$ \\
De Arte y Ciencias Sociales & Carreras & $4 \%$ & 25 & $(257 \%)$ & 24 & $(-4 \%)$ \\
ARCIS / 1999 & Sedes & $0 \%$ & 1 & $(0 \%)$ & 1 & $(0 \%)$ \\
De Ciencias de & Carreras & $0 \%$ & 13 & $(0 \%)$ & 18 & $(38 \%)$ \\
la Informática / 2003* & Sedes & $0 \%$ & 1 & $(0 \%)$ & 1 & $(0 \%)$ \\
De Viña del Mar / 2000 & Carreras & $12,6 \%$ & 26 & $(86 \%)$ & 32 & $(23 \%)$ \\
& Sedes & $0 \%$ & 2 & $(0 \%)$ & 2 & $(0 \%)$ \\
Del Mar / 2002* & Carreras & $2 \%$ & 17 & $(0 \%)$ & 27 & $(59 \%)$ \\
Internacional Sek / 2002 & Sedes & $0 \%$ & 1 & $(0 \%)$ & 10 & $(900 \%)$ \\
& Carreras & $19,4 \%$ & 104 & $(285 \%)$ & 246 & $(137 \%)$ \\
& Sedes & $0 \%$ & 1 & $(0 \%)$ & 1 & $(0 \%)$ \\
& Carreras & $-2,8 \%$ & 6 & $(0 \%)$ & 11 & $(83 \%)$ \\
& & & & & &
\end{tabular}




\begin{tabular}{llrrrrr} 
La República / 2001* & Sedes & $0 \%$ & 1 & $(0 \%)$ & 2 & $(100 \%)$ \\
& Carreras & $4,5 \%$ & 10 & $(-23 \%)$ & 26 & $(160 \%)$ \\
Mariano Egaña / 2001 & Sedes & $0 \%$ & 1 & $(0 \%)$ & 1 & $(0 \%)$ \\
& Carreras & $37,5 \%$ & 3 & $(-40 \%)$ & 8 & $(167 \%)$ \\
San Sebastián / 2001 & Sedes & $0 \%$ & 1 & $(0 \%)$ & 2 & $(0 \%)$ \\
& Carreras & $6 \%$ & 13 & $(30 \%)$ & 28 & $(115 \%)$ \\
U. Santo Tomás / 2003* & Sedes & $0 \%$ & 11 & $(1000 \%)$ & 12 & $(9 \%)$ \\
& Carreras & $8,2 \%$ & 110 & $(511 \%)$ & 127 & $(15 \%)$ \\
Pérez Rosales / 2001 & Sedes & $0 \%$ & 1 & $(0 \%)$ & 1 & $(0 \%)$ \\
& Carreras & $5 \%$ & 8 & $(14 \%)$ & 26 & $(225 \%)$ \\
\hline
\end{tabular}

* Estas instituciones obtuvieron la certificación de su autonomía en el mes de enero, lo que explica que, en algunos casos, el cambio en la tasa de crecimiento sea el mismo año de la autonomía.

Nota: Se eliminó de esta lista al Instituto Profesional Latinoamericano de Comercio Exterior, ya que no tenía información completa sobre sus carreras.

De este conjunto de instituciones, hay seis que crecieron en el año de la autonomía o en el año posterior a la certificación de ésta de manera significativamente superior a los años anteriores, tanto en términos de la cantidad de carreras que ofrecen como de las sedes que abren.

Por otra parte, en doce de ellas se han multiplicado los programas de pregrado ofrecidos sin extenderse en la misma proporción las sedes en otras ciudades del país. En la mayoría de estas instituciones la variación de carreras supera el 100\%, destacando los incrementos de la Universidad Autónoma del Sur, que alcanza un $300 \%$ el año siguiente, el Instituto Profesional Diego Portales y la Universidad Santo Tomás, con una variación cercana a 500\%, y el Instituto Profesional AIEP, que se distancia de todos los otros casos elevándose por sobre $4.000 \%$.

La evolución del número de sedes, aun cuando no presenta en general tasas tan elevadas de crecimiento, no deja de tener una

5 Cabe precisar que la situación del Instituto Profesional AIEP está relacionada con la adquisición de éste por parte de la Universidad Nacional Andrés Bello, tras la cual todos los programas académicos del Centro de Formación Técnica AIEP fueron traspasados al Instituto Profesional, por lo que no es posible determinar con los datos disponibles cuánto de este aumento de sedes y carreras corresponde estrictamente a programas académicos y sedes nuevas. 
multiplicación significativa, considerando los costos asociados a la instalación de un nuevo inmueble y las consecuencias que trae para la zona la creación de la nueva sede. Destacan en esto el Instituto Profesional AIEP, que alcanza una variación de 250\% un año después de su autonomía; el Instituto Profesional Diego Portales, con un 300\% de aumento; la Universidad del Mar, que se eleva en $900 \%$, y la Universidad Santo Tomás cuya variación es de $1.000 \%$.

Es necesario señalar que la tendencia de crecimiento de sedes y carreras en todas las instituciones cuya autonomía ha sido certificada por el Consejo Superior de Educación se explica también porque algunas instituciones de este grupo, habiendo obtenido su autonomía anteriormente, muestran una aceleración de su crecimiento en sedes y carreras sólo desde esta década.

Así ocurre con el Instituto Profesional La Araucana, cuya autonomía fue certificada en 1998 y recién en 2000 muestra un crecimiento de carreras de 367\%. El Instituto Profesional del Valle Central, que obtuvo su autonomía en 1996, sólo el año 2000 incrementa su número de carreras en un 133\% y en 2003 crece en $188 \%$, mientras que la cantidad de sedes aumenta en un $100 \%$ en el año 2001. En el caso del Instituto Profesional ARCOS, además de observarse un incremento de carreras en el año posterior a su autonomía -que tuvo lugar en 1999-, se aprecia una nueva expansión considerable en el 2004, donde crece un 100\% en el número de carreras y un $150 \%$ en la cantidad de sedes. El Instituto Profesional Santo Tomás dobla en el año 2002 su número de sedes y continúa su aumento en el año 2003 con un 70\% más, tres años después de la autonomía. La Universidad Central pasa de una a tres sedes en 2003, habiendo logrado su autonomía en 1993. La Universidad ARCIS presenta un crecimiento de $100 \%$ en sus carreras en 2003, cuatro años después de su autonomía, un aumento de una a tres sedes en el año 2002, y de tres a nueve sedes en el año 2003. El número de sedes de la Universidad de Viña del Mar pasa de dos a cinco en 2004, habiendo certificado su autonomía en 2000. 
La Universidad de Las Américas experimenta expansiones importantes de carreras en los años 2000 (378\%) y 2002 (166\%), habiendo certificado su autonomía en 1997. En la Universidad Diego Portales hay un aumento importante de carreras en 2001, que representa una variación de $126 \%$ respecto del año anterior, aun cuando su autonomía fue otorgada ocho años antes. La Universidad La República aumenta sus sedes de dos a ocho en 2003, dos años después de su autonomía; y la evolución del número de carreras en la Universidad Mayor alcanza su mayor variación en el año 2000, siendo una institución autónoma desde el año 1996.

De este modo, al igual que en el caso del crecimiento de la matrícula, se identifican dos elementos que explican la evolución ascendente del número de sedes y carreras en el sistema. En primer término, hay un conjunto de instituciones cuya autonomía fue certificada a principios de esta década y que, inmediatamente después, crearon nuevos programas académicos, en la misma sede que han utilizado o en nuevas sedes en otras regiones del país. En segundo lugar, hay algunas que, habiendo transcurrido varios años desde su autonomía, han optado recientemente por ofrecer nuevas carreras y por abrir nuevas sedes. El efecto de estos dos fenómenos genera un aceleramiento en el aumento de carreras y sedes desde el año 2001, que se observaba en los gráficos 4 y 5.

\section{La ampliación en las áreas del conocimiento}

Las áreas del conocimiento remiten a una clasificación de disciplinas similares o afines, las que se agrupan conforme a determinadas convenciones del mundo académico. El CSE utiliza una clasificación que reconoce diez áreas del conocimiento:

- Administración y comercio

- Agropecuaria

- Arte y arquitectura

- Ciencias

- Ciencias sociales 
- Derecho

- Humanidades

- Educación

- Tecnología

- Salud

Considerando esta clasificación, es posible señalar que la cantidad de áreas del conocimiento que estas instituciones cubren también ha crecido en el periodo analizado. En efecto, si en el año 1996 las instituciones ofrecían programas en cuatro áreas en promedio, en el año 2004 lo hicieron en alrededor de 6,4 áreas. Ello se aprecia en el siguiente gráfico.

Gráfico 5

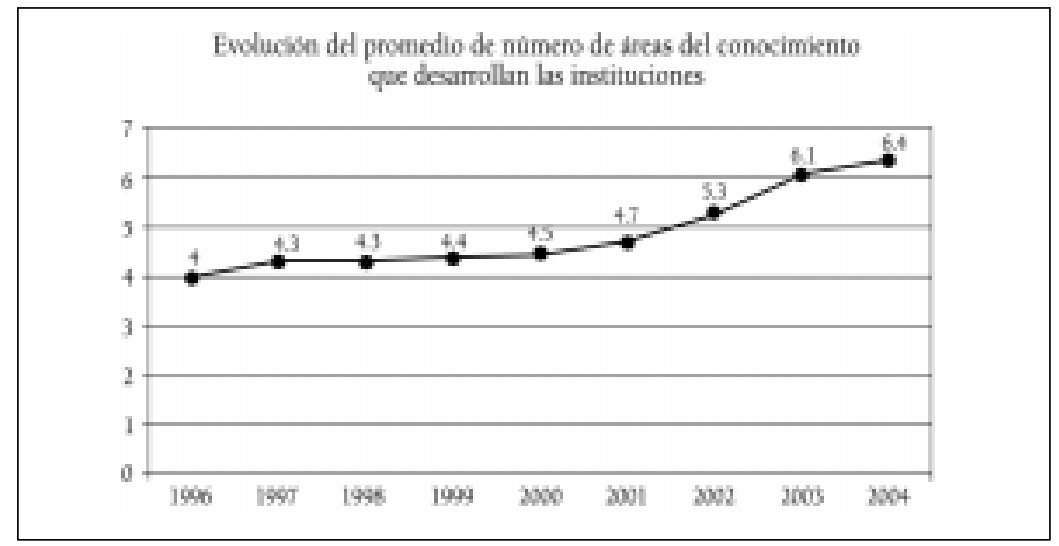

Estas cifras prácticamente no difieren de las observadas en la totalidad de las universidades e institutos profesionales del sistema de educación superior. Según datos de INDICES 1997 y 2005, el promedio de áreas del conocimiento que las instituciones cubrían en 1996 era de 3,9 áreas y en 2004 es de 5,7 áreas.

De manera similar a las tendencias de matrícula, sedes y carreras, la cantidad de áreas del conocimiento en las 35 instituciones analizadas se ha ampliado, particularmente desde el año 2002 en 


\section{adelante. A continuación se analiza si el aumento del número de áreas en cada institución se produce inmediatamente después de la certificación de su autonomía.}

Tabla 5: Número y variación anual de áreas del conocimiento. Antes y después de la autonomía.

\begin{tabular}{lrrrrrr}
\hline Institución / Año autonomía & $\begin{array}{c}\text { Año anterior } \\
\text { autonomía }\end{array}$ & $\begin{array}{r}\text { Año } \\
\text { autonomía }\end{array}$ & $\begin{array}{r}\text { Año posterior } \\
\text { autonomía }\end{array}$ \\
\hline INSTITUTOS PROFESIONALES & & & & & & \\
\hline AIEP / 2002* & 3 & $(0 \%)$ & 3 & $(0 \%)$ & 8 & $(167 \%)$ \\
De Artes y Comunicación ARCOS / 1999 & 2 & $(0 \%)$ & 2 & $(0 \%)$ & 2 & $(0 \%)$ \\
Diego Portales / 2001 & 5 & $(-17 \%)$ & 6 & $(20 \%)$ & 6 & $(0 \%)$ \\
EATRI / 2002 & $2(100 \%)$ & 1 & $(-50)$ & 3 & $(200 \%)$ \\
ESUCOMEX / 2002* & 2 & $(0 \%)$ & 2 & $(0 \%)$ & 2 & $(0 \%)$ \\
La Araucana / 1998 & 2 & $(0 \%)$ & 2 & $(0 \%)$ & 2 & $(0 \%)$ \\
Santo Tomás / 2000 & 5 & $(0 \%)$ & 5 & $(0 \%)$ & 5 & $(0 \%)$ \\
\hline UNIVERSIDADES & & & & & & \\
\hline Academia de Humanismo Cristiano / 1999 & 5 & $(0 \%)$ & 5 & $(0 \%)$ & 6 & $(20 \%)$ \\
Andrés Bello / 1999 & 8 & $(14 \%)$ & 8 & $(0 \%)$ & 10 & $(25 \%)$ \\
Autónoma del Sur / 2002 & 6 & $(0 \%)$ & 6 & $(0 \%)$ & 6 & $(0 \%)$ \\
Bolivariana / 2002* & 3 & $(0 \%)$ & $7(133 \%)$ & 7 & $(0 \%)$ \\
Católica Silva Henríquez / 2003* & 3 & $(0 \%)$ & 3 & $(0 \%)$ & 3 & $(0 \%)$ \\
De Arte y Ciencias Sociales ARCIS / 1999 & 6 & $(0 \%)$ & 6 & $(0 \%)$ & 6 & $(0 \%)$ \\
De Artes, Ciencias y Comunicación UNIACC/1999) & 3 & $(0 \%)$ & 4 & $(33 \%)$ & 3 & $(-25 \%)$ \\
De Ciencias de la Informática / 2003* & 4 & $(0 \%)$ & 6 & $(50 \%)$ & 6 & $(0 \%)$ \\
De Las Américas / 1997 & 6 & $(\mathrm{~s} / \mathrm{i})$ & 6 & $(0 \%)$ & 6 & $(0 \%)$ \\
De Viña del Mar / 2000 & 7 & $(0 \%)$ & 6 & $(-14 \%)$ & 7 & $(17 \%)$ \\
Del Desarrollo / 1997* & 6 & $(\mathrm{~s} / \mathrm{i})$ & 6 & $(0 \%)$ & 5 & $(-17 \%)$ \\
Del Mar / 2002* & 6 & $(0 \%)$ & 9 & $(50 \%)$ & 10 & $(11 \%)$ \\
Internacional Sek / 2002 & 4 & $(0 \%)$ & 4 & $(0 \%)$ & 5 & $(25 \%)$ \\
La República / 2001* & 7 & $(0 \%)$ & 5 & $(-29 \%)$ & 8 & $(60 \%)$ \\
Mariano Egaña / 2001 & 1 & $(0 \%)$ & 1 & $(0 \%)$ & 4 & $(300 \%)$ \\
San Sebastián / 2001 & 5 & $(0 \%)$ & 5 & $(0 \%)$ & 7 & $(40 \%)$ \\
Santo Tomás / 2003* & 5 & $(0 \%)$ & 7 & $(40 \%)$ & 9 & $(29 \%)$ \\
Pérez Rosales / 2001 & 3 & $(0 \%)$ & 3 & $(0 \%)$ & 3 & $(0 \%)$ \\
\hline & & & & &
\end{tabular}

*Estas instituciones obtuvieron la certificación de su autonomía en el mes de enero, lo que explica que, en algunos casos, el cambio en la tasa de crecimiento sea el mismo año de la autonomía.

Nota: Se eliminó de esta lista al Instituto Profesional Latinoamericano de Comercio Exterior, ya que no presenta información completa sobre áreas del conocimiento. 
Hay algunas instituciones que amplían las áreas del conocimiento en que imparten programas inmediatamente después de su autonomía, aunque no todas lo hacen en la misma proporción. En efecto, el Instituto Profesional AIEP y las universidades Bolivariana, Del Mar, La República, Mariano Egaña y Santo Tomás muestran aumentos más significativos de un año al siguiente.

El incremento en el promedio de la cantidad de áreas desarrolladas observado en el gráfico 6 se asocia muy fuertemente a un grupo de instituciones cuya autonomía no fue certificada recientemente. Es el caso del Instituto Profesional ARCOS que obtuvo su autonomía en 1999 y aumentó las áreas que desarrolla de dos a cinco en 2004; el Instituto Profesional del Valle Central duplicó la cantidad de áreas en que ofrece programas desde cuatro a ocho en el 2003, habiendo tenido lugar su autonomía en 1996; asimismo, el Instituto Profesional La Araucana se expandió en dos nuevas áreas el año 2003, pasando de tres a cinco de un año al siguiente, en circunstancias que su autonomía fue certificada en 1998; la Universidad Academia de Humanismo Cristiano elevó en dos el número de áreas en el año 2002, tres años después de su autonomía; lo mismo hizo la Universidad del Desarrollo en el mismo año, luego de cinco años como institución autónoma; la Universidad Pérez Rosales muestra un aumento significativo de áreas en 2003, dos años después de su autonomía, pasando de tres áreas a siete, entre un año y el siguiente.

Así, la ampliación de la gama de áreas en que las instituciones ofrecen programas académicos se da principalmente entre los años 2001 y 2004, en parte a causa de instituciones cuya certificación de autonomía ha sido certificada en esos años y, en buena medida, a raíz de decisiones de desarrollo de instituciones más antiguas que gozan de autonomía hace varios años. Si bien, a grandes rasgos, el crecimiento en áreas del conocimiento no resulta tan impresionante como en otros indicadores, las implicaciones de incursionar en una nueva área no son menores, pues normalmente suponen iniciar nuevos programas académicos, modificar en algún aspecto al menos la estructura 
organizativa, implementar mayor infraestructura o equipamiento, disponer de recursos administrativos, contratar nuevos docentes, y muchas de esas acciones suponen, a su vez, importantes inversiones.

De las cifras analizadas se desprende una tendencia que habla, primero, de un crecimiento intensivo, con aumentos de matrícula en las mismas carreras o en carreras afines, intensificando y reciclando capacidades institucionales previas en el área. En un segundo momento, se aprecia un crecimiento extensivo, caracterizado por la apertura a nuevas áreas disciplinarias, en algunos casos, que se da probablemente cuando se ha agotado la demanda previa y se requiere dar un salto en el desarrollo institucional.

\section{Comportamiento regional del crecimiento}

Los índices de crecimiento analizados hasta ahora dan cuenta de una expansión, a lo largo del tiempo, de la mayoría de las instituciones cuya autonomía ha sido certificada por el CSE. En otras palabras, se sabe que muchas de estas instituciones han aumentado su matrícula, iniciado nuevas carreras, abierto nuevas sedes y/o han incursionado en nuevas áreas del conocimiento. No obstante, se desconoce cómo se distribuye este crecimiento regionalmente en el país.

En primer lugar, se revisa la distribución de las sedes de estas 35 instituciones entre las 13 regiones del país en el periodo 19962004. La siguiente tabla muestra dicha distribución.

Tabla 6: Distribución regional de las sedes de las instituciones.

\begin{tabular}{lcccccccrr}
\hline & 1996 & 1997 & 1998 & 1999 & 2000 & 2001 & 2002 & 2003 & 2004 \\
\hline Región I & 0 & 0 & 0 & 0 & 0 & 0 & 1 & 7 & 7 \\
Región II & 2 & 2 & 2 & 2 & 2 & 1 & 2 & 8 & 10 \\
Región III & 0 & 0 & 0 & 0 & 0 & 0 & 0 & 0 & 2 \\
Región IV & 1 & 1 & 1 & 2 & 2 & 3 & 3 & 8 & 8 \\
Región V & 4 & 4 & 4 & 4 & 5 & 5 & 6 & 9 & 10 \\
Región VI & 1 & 0 & 0 & 0 & 0 & 0 & 0 & 3 & 5 \\
Región VII & 2 & 2 & 3 & 4 & 4 & 5 & 5 & 12 & 13 \\
Región VIII & 4 & 4 & 4 & 4 & 4 & 4 & 10 & 24 & 27 \\
Región IX & 1 & 1 & 1 & 1 & 1 & 3 & 4 & 5 & 5 \\
Región X & 1 & 1 & 1 & 1 & 1 & 3 & 6 & 9 & 12 \\
Región XI & 0 & 0 & 0 & 0 & 0 & 0 & 0 & 0 & 0
\end{tabular}




\begin{tabular}{lrrrrrrrrr} 
Región XII & 0 & 0 & 0 & 0 & 0 & 0 & 0 & 2 & 4 \\
$\begin{array}{l}\text { Región } \\
\text { Metropolitana }\end{array}$ & 25 & 25 & 26 & 27 & 27 & 28 & 29 & 31 & 32 \\
\hline Total & 41 & 40 & 42 & 45 & 46 & 52 & 66 & 118 & 135 \\
\hline
\end{tabular}

Hacia principios del periodo, las sedes estaban bastante más centralizadas en el área metropolitana (62\% de las sedes) y en las dos regiones más pobladas luego de ella, las regiones V y VIII (el 10\% cada una). Asimismo, en ese año había regiones que no presentaban sedes de estas instituciones, como las regiones I, III, XI y XII.

Gráfico 6

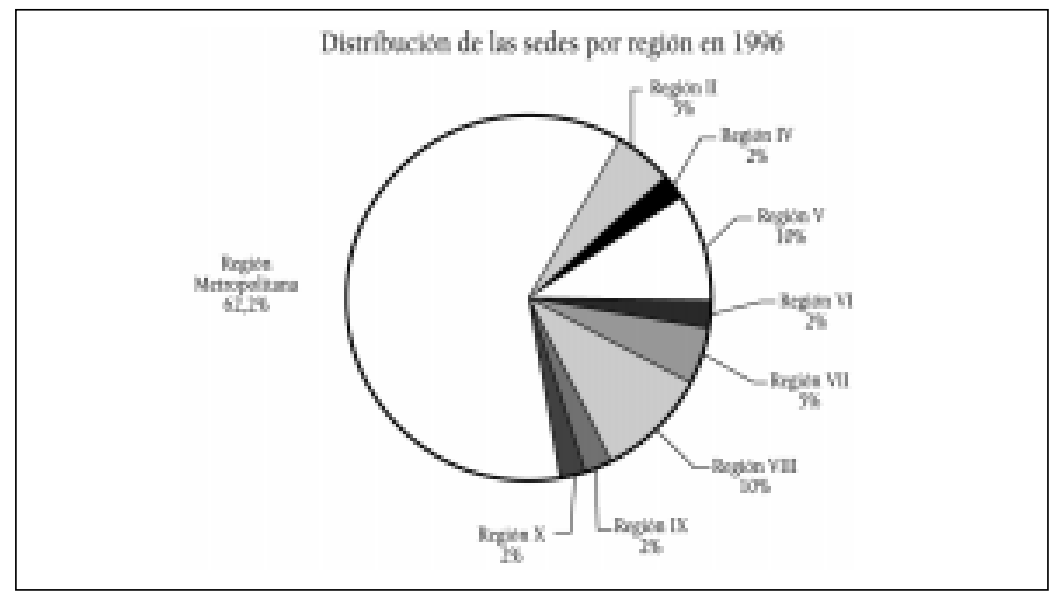

Hacia finales del periodo todas las regiones del país cuentan con sedes, excepto la Región XI. Por su parte, la Región Metropolitana concentra una proporción bastante menor del total de sedes de este grupo de instituciones. Efectivamente, en 2004 esta Región reúne el 24\% de las sedes, la Región VIII el 20\% y el porcentaje restante se distribuye entre las otras regiones del país.

A lo largo del periodo hay regiones que aumentan su número de sedes de forma significativa, como las regiones VII y X, aun cuando ellas no corresponden necesariamente a las con mayor población. De ese modo, el panorama regional en el año 2004 se refleja en el gráfico siguiente. 
Gráfico 7

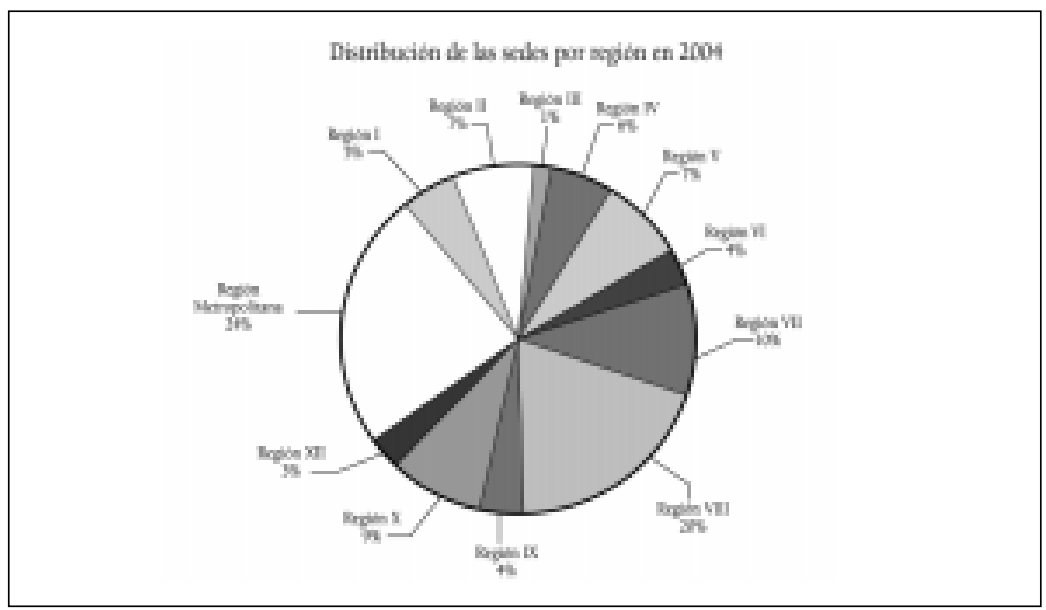

Actualmente, la cobertura de estas instituciones parece estar más distribuida a lo largo del país, aunque no necesariamente en las zonas con mayor cantidad de habitantes. Esto podría estar indicando que las instituciones de educación superior más nuevas están optando por expandirse hacia zonas tradicionalmente no cubiertas por las más antiguas, zonas que, si bien poseen una menor población, presentan también una menor oferta de programas académicos y, por lo tanto, menos competencia.

El análisis individual de la apertura de sedes durante este periodo permite constatar que hay un conjunto no menor de instituciones que ha abierto recientemente sedes en localidades de relativamente baja población. Es el caso de instituciones como las universidades Bolivariana, ARCIS, De Viña del Mar y La República. Ello se puede apreciar en la siguiente tabla que identifica a las universidades e institutos profesionales que han abierto mayor cantidad de sedes y las ciudades en que se ubican éstas. 


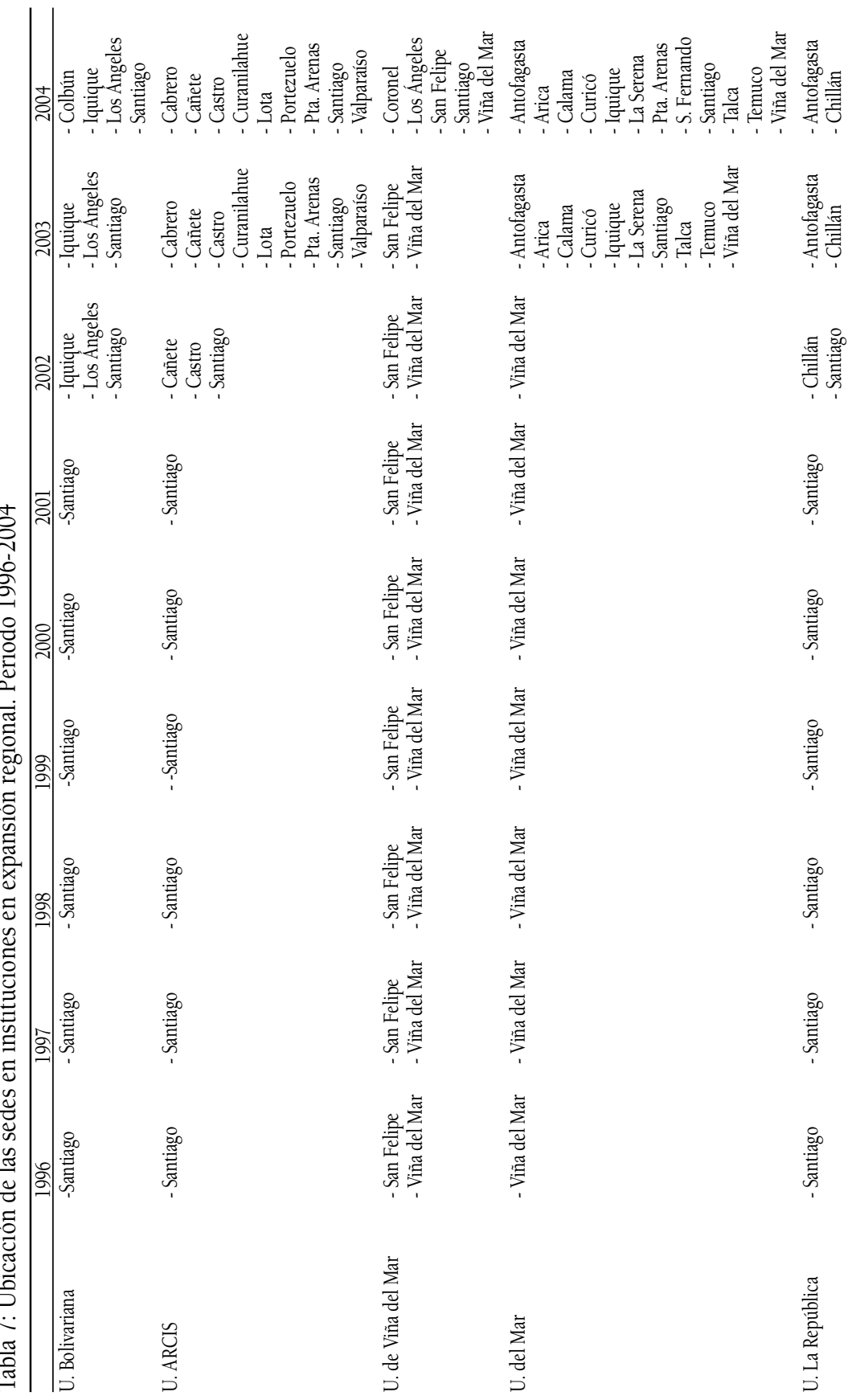




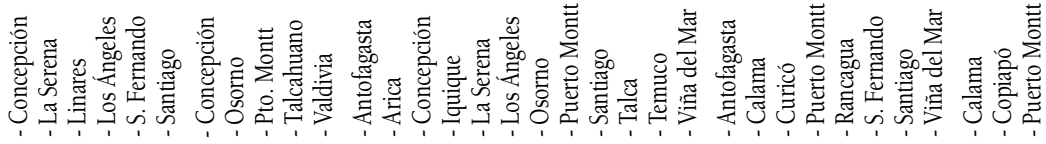

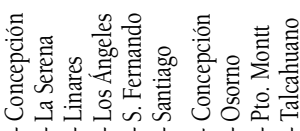
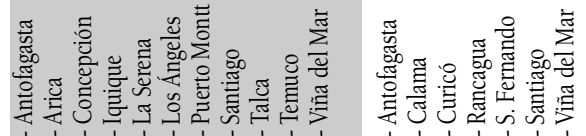

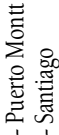

:

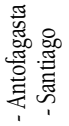

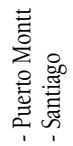

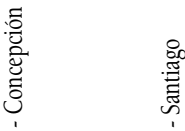

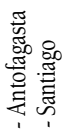

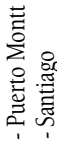

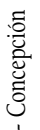

.

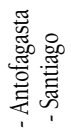

苞

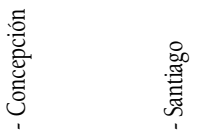

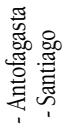

焉

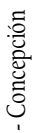

.্:

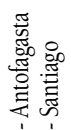

.

:

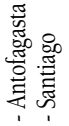

:

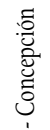

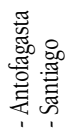

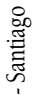

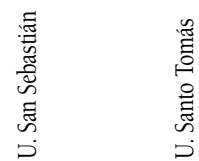

崖

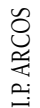




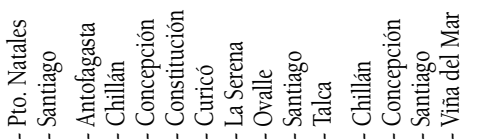

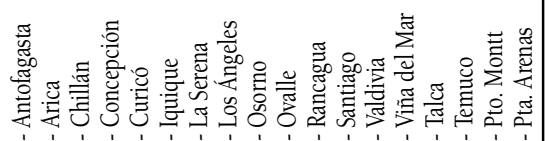

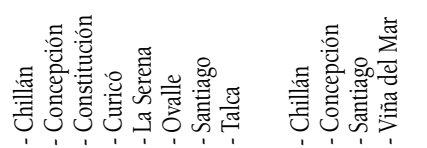

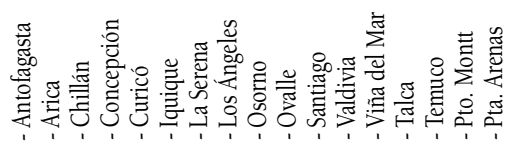

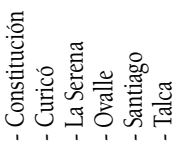

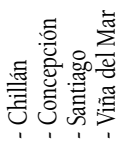

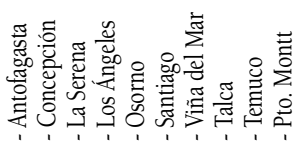

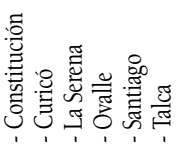

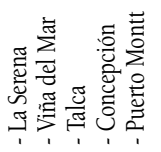

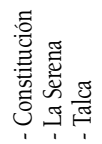

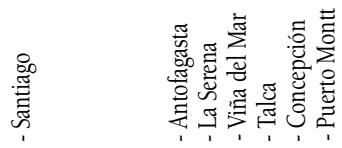

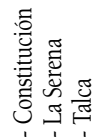

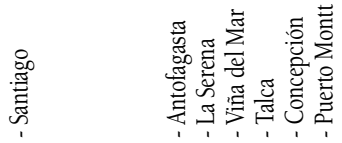

$\frac{\sqrt{\pi}}{\sqrt[\pi]{4}}$

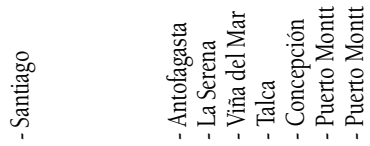

$\frac{\pi}{\frac{\pi}{\pi}}$

:

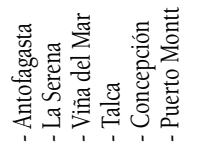

$\stackrel{\frac{\pi}{\pi}}{\stackrel{\pi}{\pi}}$

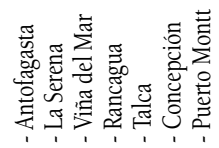

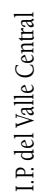

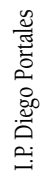

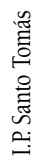


Llama la atención que, prácticamente, no hay instituciones que se expandan geográficamente en ciudades dentro de una misma región o una misma zona del país. Sólo la Universidad San Sebastián parece haberlo hecho selectivamente en la zona centro sur del país (regiones VIII y X).

\section{Comportamiento global de los indicadores de crecimiento}

Las cifras en todos los indicadores analizados en esta sección muestran que existe una expansión de este grupo de instituciones y que dicho crecimiento ha sido particularmente elevado en los últimos años. Así se aprecia al analizar su variación año tras año, la que normalmente presenta sus cifras más altas entre 2002 y 2003, a excepción de la cantidad de carreras que presenta un aumento brusco en 2000 para después volver a descender hasta el año 2002.

Tabla 8: Variación anual en los indicadores de crecimiento

\begin{tabular}{lrrrrrrrr}
\hline Indicador & 1997 & 1998 & 1999 & 2000 & 2001 & 2002 & 2003 & 2004 \\
\hline Matrícula 1 $1^{\text {er }}$ año & $13 \%$ & $8 \%$ & $7 \%$ & $27 \%$ & $8 \%$ & $32 \%$ & $28 \%$ & $11 \%$ \\
Matrícula total & $9 \%$ & $5 \%$ & $12 \%$ & $16 \%$ & $7 \%$ & $17 \%$ & $23 \%$ & $15 \%$ \\
Sedes & $-2 \%$ & $3 \%$ & $7 \%$ & $2 \%$ & $13 \%$ & $29 \%$ & $79 \%$ & $14 \%$ \\
Carreras & $2 \%$ & $4 \%$ & $5 \%$ & $69 \%$ & $29 \%$ & $55 \%$ & $71 \%$ & $16 \%$ \\
Promedio N ${ }^{\circ}$ de áreas & $8 \%$ & $0 \%$ & $2 \%$ & $2 \%$ & $4 \%$ & $13 \%$ & $15 \%$ & $5 \%$ \\
\hline
\end{tabular}

Entre todos los indicadores de crecimiento analizados, los incrementos más drásticos de un año al siguiente se dan en la cantidad de sedes que las instituciones abren y en el número de carreras que ofrecen, alcanzando en algunos años variaciones cercanas al 70\%. Resulta interesante constatar que las cifras más elevadas se presentan en dos de los indicadores que corresponden a variables que dan cuenta fundamentalmente de la oferta educacional, no así en la matrícula que depende más directamente de la demanda, lo que sugiere que no siempre se están llenando las vacantes de los programas académicos ofrecidos.

Estas cifras confirman la coincidencia entre la expansión de las instituciones en los últimos años y los periodos en que se han 
certificado mayor cantidad de autonomías. No obstante, como se vio en el análisis más detallado de los indicadores, no sólo se aprecia una expansión de la oferta de varias instituciones inmediatamente después de la obtención de su autonomía, sino también un crecimiento que es efecto de la expansión reciente de instituciones que son autónomas hace varios años. En efecto, pareciera que el crecimiento acelerado de algunas instituciones en el último periodo puede explicarse también por factores de mercado en un contexto de desregulación en la educación superior, todo ello en un escenario que, a principios de esta década, se había modificado sustancialmente en virtud de una gran cantidad de autonomías institucionales que se han certificado y que han permitido un crecimiento inédito de las instituciones más jóvenes de este grupo.

Es posible que en esta ampliación de la oferta hayan interactuado dos fuerzas. Por una parte, las instituciones más jóvenes y de reciente autonomía incrementan su oferta como reacción inmediata a su recién estrenada condición en el contexto de un mercado que crece. A su vez, las instituciones que han sido autónomas desde hace algún tiempo expanden su oferta con particular fuerza en los últimos años, como parte de una estrategia de sobrevivencia o de supremacía, en un escenario en que entran a competir nuevas instituciones en igualdad de condiciones.

Por último, llama la atención que las cifras globales de variación de 2004 muestren una desaceleración del crecimiento. Aunque es pronto para afirmarlo, es posible que ello sea señal de una estabilización del sistema que determine que, en los próximos años, estas instituciones de educación superior crezcan a un ritmo menor que el observado en el último tiempo. También podría responder a un agotamiento de la demanda por estudios de corte tradicional, como son las carreras universitarias de ocho o diez semestres que normalmente conocemos, agotamiento que hará que las instituciones se vean obligadas a desarrollarse de modo más extensivo explorando una oferta no tradicional, como podrían ser programas de menor duración, educación online, entre otros. 


\section{La evolución de indicadores asociados al proceso de enseñanza-aprendizaje}

Uno de los objetivos de este estudio es determinar si, junto con el crecimiento de las instituciones, se experimenta un aumento de algunos factores que intervienen en la efectividad del proceso de enseñanza-aprendizaje. Las variables que influyen en dicho proceso son muchas, tales como la calidad y cantidad de los docentes contratados, el nivel de formación de los alumnos que ingresan, la disponibilidad de recursos bibliográficos y educacionales, la calidad de los programas académicos impartidos, entre otras múltiples situaciones. No obstante, hay algunas de esas variables que presentan dificultades para su medición, o bien, de las cuales no existen datos sistematizados. Por lo tanto, se analizan las cifras que están disponibles en el CSE relativas a los docentes contratados por las instituciones y a los recursos bibliográficos de que disponen, contrastándolas con el comportamiento de la matrícula total de las instituciones, a fin de obtener pistas acerca de si su crecimiento ha sido armonioso respecto de esas áreas.

\section{Evolución de los recursos docentes}

La cantidad y las características de los académicos que una institución contrata son factores esenciales para mantener una adecuada relación profesor-alumno y así lograr un proceso de enseñanza-aprendizaje eficaz; por lo tanto, si una institución aumenta su contingente de estudiantes, se espera que incremente el número de los profesores que los atienden.

\subsection{La cantidad de académicos en las instituciones}

Las instituciones que obtuvieron su autonomía tras la acreditación con el CSE muestran un crecimiento de sus cuerpos académicos en la medida que se ha elevado su matrícula, aunque no siempre de manera regular como se ve en la tabla siguiente. 
Tabla 9: Variación matrícula total y variación número de docentes.

\begin{tabular}{|c|c|c|c|c|c|c|c|c|c|c|}
\hline \multirow{2}{*}{\multicolumn{2}{|c|}{ INSTITUTOS PROFESIONALES }} & 1997 & 1998 & 1999 & 2000 & 2001 & 2002 & 2003 & 2004 & Promedio \\
\hline & & & & & & & & & & \\
\hline \multirow[t]{2}{*}{$\operatorname{AIEP}^{*}$} & Matrícula & $12 \%$ & $6 \%$ & $-13 \%$ & $-9 \%$ & $-31 \%$ & $10 \%$ & $694 \%$ & $34 \%$ & $88 \%$ \\
\hline & Docentes & $23 \%$ & $-19 \%$ & $1 \%$ & $-15 \%$ & $-9 \%$ & $-8 \%$ & $580 \%$ & $76 \%$ & $79 \%$ \\
\hline \multirow[t]{2}{*}{ Carlos Casanueva } & Matrícula & $9 \%$ & $-1 \%$ & $6 \%$ & $10 \%$ & $17 \%$ & $13 \%$ & $26 \%$ & $-3 \%$ & $10 \%$ \\
\hline & Docentes & $8 \%$ & $0 \%$ & $27 \%$ & $-8 \%$ & $-7 \%$ & $-12 \%$ & $50 \%$ & $15 \%$ & $9 \%$ \\
\hline \multirow[t]{2}{*}{ EATRI } & Matrícula & $20 \%$ & $20 \%$ & $-11 \%$ & $-19 \%$ & $3 \%$ & $-5 \%$ & $2 \%$ & $31 \%$ & $5 \%$ \\
\hline & Docentes & $-4 \%$ & $24 \%$ & $-10 \%$ & $-11 \%$ & $8 \%$ & $-19 \%$ & $0 \%$ & $45 \%$ & $4 \%$ \\
\hline \multirow[t]{2}{*}{ Santo Tomás } & Matrícula & $8 \%$ & $-3 \%$ & $0 \%$ & $1 \%$ & $-4 \%$ & $68 \%$ & $11 \%$ & $0 \%$ & $10 \%$ \\
\hline & Docentes & $-18 \%$ & $28 \%$ & $44 \%$ & $-33 \%$ & $16 \%$ & $28 \%$ & $6 \%$ & $43 \%$ & $14 \%$ \\
\hline \multicolumn{11}{|l|}{ UNIVERSIDADES } \\
\hline Academia de & Matrícula & $60 \%$ & $1 \%$ & $8 \%$ & $19 \%$ & $16 \%$ & $14 \%$ & $6 \%$ & $5 \%$ & $16 \%$ \\
\hline Humanismo Cristiano & Docentes & $-24 \%$ & $52 \%$ & $-4 \%$ & $4 \%$ & $13 \%$ & $-1 \%$ & $58 \%$ & $-3 \%$ & $12 \%$ \\
\hline \multirow[t]{2}{*}{ Alberto Hurtado } & Matrícula & & & $88 \%$ & $170 \%$ & $7 \%$ & $50 \%$ & $38 \%$ & $25 \%$ & $63 \%$ \\
\hline & Docentes & & & $74 \%$ & 139 & $78 \%$ & $18 \%$ & $39 \%$ & $13 \%$ & $60 \%$ \\
\hline \multirow[t]{2}{*}{ Andrés Bello } & Matrícula & $0 \%$ & $0 \%$ & $3 \%$ & $66 \%$ & $6 \%$ & $23 \%$ & $4 \%$ & $13 \%$ & $14 \%$ \\
\hline & Docentes & $-13 \%$ & $5 \%$ & $-4 \%$ & $51 \%$ & $20 \%$ & $18 \%$ & $15 \%$ & $7 \%$ & $12 \%$ \\
\hline \multirow[t]{2}{*}{ Católica Silva Henríquez* } & Matrícula & $11 \%$ & $-3 \%$ & $-4 \%$ & $-2 \%$ & $-5 \%$ & $-1 \%$ & $-1 \%$ & $6 \%$ & $0 \%$ \\
\hline & Docentes & $-1 \%$ & $-2 \%$ & $0 \%$ & $77 \%$ & $-51 \%$ & $-5 \%$ & $5 \%$ & $-4 \%$ & $2 \%$ \\
\hline De Arte y Ciencias & Matrícula & $-2 \%$ & $13 \%$ & $4 \%$ & $9 \%$ & $48 \%$ & $-1 \%$ & $9 \%$ & $-5 \%$ & $9 \%$ \\
\hline Sociales ARCIS & Docentes & $-15 \%$ & $-14 \%$ & $9 \%$ & $1 \%$ & $97 \%$ & $-42 \%$ & $168 \%$ & $6 \%$ & $26 \%$ \\
\hline De Artes, Ciencias y & Matrícula & $8 \%$ & $12 \%$ & $2 \%$ & $24 \%$ & $8 \%$ & $13 \%$ & $12 \%$ & $7 \%$ & $11 \%$ \\
\hline Comunicación UNIACC & Docentes & $7 \%$ & $15 \%$ & $-1 \%$ & $42 \%$ & $5 \%$ & $30 \%$ & $25 \%$ & $-1 \%$ & $15 \%$ \\
\hline De Ciencias de la & Matrícula & $29 \%$ & $13 \%$ & $21 \%$ & $14 \%$ & $7 \%$ & $-15 \%$ & $41 \%$ & $3 \%$ & $14 \%$ \\
\hline Informática* & Docentes & $9 \%$ & $-43 \%$ & $15 \%$ & $27 \%$ & $3 \%$ & $5 \%$ & $0 \%$ & $15 \%$ & $4 \%$ \\
\hline \multirow[t]{2}{*}{ De Las Américas } & Matrícula & $19 \%$ & $21 \%$ & $54 \%$ & $57 \%$ & $63 \%$ & $48 \%$ & $36 \%$ & $29 \%$ & $41 \%$ \\
\hline & Docentes & $16 \%$ & $5 \%$ & $13 \%$ & $23 \%$ & $46 \%$ & $41 \%$ & $34 \%$ & $29 \%$ & $26 \%$ \\
\hline \multirow[t]{2}{*}{ Del Desarrollo* } & Matrícula & $25 \%$ & $13 \%$ & $91 \%$ & $10 \%$ & $17 \%$ & $13 \%$ & $3 \%$ & $6 \%$ & $22 \%$ \\
\hline & Docentes & $19 \%$ & $-7 \%$ & $219 \%$ & $-2 \%$ & $29 \%$ & $7 \%$ & $24 \%$ & $18 \%$ & $39 \%$ \\
\hline \multirow[t]{2}{*}{ Del Mar* } & Matrícula & $22 \%$ & $4 \%$ & $16 \%$ & $0 \%$ & $0 \%$ & $10 \%$ & $112 \%$ & $41 \%$ & $26 \%$ \\
\hline & Docentes & $-6 \%$ & $0 \%$ & $-25 \%$ & $13 \%$ & $-16 \%$ & $6 \%$ & $138 \%$ & $54 \%$ & $20 \%$ \\
\hline \multirow[t]{2}{*}{ Diego Portales } & Matrícula & $1 \%$ & $11 \%$ & $0 \%$ & $4 \%$ & $0 \%$ & $-10 \%$ & $24 \%$ & $-5 \%$ & $3 \%$ \\
\hline & Docentes & $10 \%$ & $7 \%$ & $2 \%$ & $11 \%$ & $3 \%$ & $22 \%$ & $-29 \%$ & $47 \%$ & $9 \%$ \\
\hline \multirow[t]{2}{*}{ Finis Terrae } & Matrícula & $12 \%$ & $10 \%$ & $-3 \%$ & $29 \%$ & $-11 \%$ & $13 \%$ & $0 \%$ & $10 \%$ & $7 \%$ \\
\hline & Docentes & $-43 \%$ & $11 \%$ & $22 \%$ & $38 \%$ & $11 \%$ & $38 \%$ & $12 \%$ & $31 \%$ & $15 \%$ \\
\hline Iberoamericana de & Matrícula & $4 \%$ & $-2 \%$ & $0 \%$ & $0 \%$ & $0 \%$ & $-3 \%$ & $-6 \%$ & $-12 \%$ & $-2 \%$ \\
\hline Ciencias y Tecnología & Docentes & $2 \%$ & $2 \%$ & $-2 \%$ & $58 \%$ & $-38 \%$ & $0 \%$ & $31 \%$ & $-11 \%$ & $5 \%$ \\
\hline \multirow[t]{2}{*}{ Internacional Sek } & Matrícula & $-12 \%$ & $3 \%$ & $10 \%$ & $-1 \%$ & $2 \%$ & $2 \%$ & $1 \%$ & $-15 \%$ & $-1 \%$ \\
\hline & Docentes & $-20 \%$ & $3 \%$ & $0 \%$ & $-8 \%$ & $14 \%$ & $-8 \%$ & $7 \%$ & $0 \%$ & $-2 \%$ \\
\hline \multirow[t]{2}{*}{ La República* } & Matrícula & $6 \%$ & $3 \%$ & $16 \%$ & $-1 \%$ & $10 \%$ & $17 \%$ & $11 \%$ & $11 \%$ & $9 \%$ \\
\hline & Docentes & $-11 \%$ & $-6 \%$ & $0 \%$ & $3 \%$ & $1 \%$ & $23 \%$ & $30 \%$ & $31 \%$ & $9 \%$ \\
\hline \multirow[t]{2}{*}{ Mariano Egaña } & Matrícula & $-3 \%$ & $-4 \%$ & $-14 \%$ & $2 \%$ & $-11 \%$ & $167 \%$ & $6 \%$ & $1 \%$ & $18 \%$ \\
\hline & Docentes & $8 \%$ & $-15 \%$ & $-16 \%$ & $76 \%$ & $-31 \%$ & $0 \%$ & $41 \%$ & $176 \%$ & $30 \%$ \\
\hline \multirow[t]{2}{*}{ Mayor } & Matrícula & $13 \%$ & $11 \%$ & $32 \%$ & $41 \%$ & $10 \%$ & $22 \%$ & $15 \%$ & $25 \%$ & $21 \%$ \\
\hline & Docentes & $4 \%$ & $4 \%$ & $16 \%$ & $24 \%$ & $257 \%$ & $-35 \%$ & $-1 \%$ & $27 \%$ & $37 \%$ \\
\hline San Sebastián & Matrícula & $5 \%$ & $8 \%$ & $8 \%$ & $6 \%$ & $24 \%$ & $44 \%$ & $69 \%$ & $22 \%$ & $23 \%$ \\
\hline & Docentes & $-2 \%$ & $3 \%$ & $-1 \%$ & $12 \%$ & $25 \%$ & $18 \%$ & $456 \%$ & $-52 \%$ & $57 \%$ \\
\hline Santo Tomás* & Matrícula & $31 \%$ & $13 \%$ & $3 \%$ & $8 \%$ & $-12 \%$ & $0 \%$ & $-1 \%$ & $73 \%$ & $14 \%$ \\
\hline & Docentes & $4 \%$ & $16 \%$ & $-6 \%$ & $-18 \%$ & $5 \%$ & $1 \%$ & $4 \%$ & $127 \%$ & $17 \%$ \\
\hline Pérez Rosales & Matrícula & $6 \%$ & $7 \%$ & $0 \%$ & $11 \%$ & $4 \%$ & $-3 \%$ & $-5 \%$ & $12 \%$ & $4 \%$ \\
\hline & Docentes & $71 \%$ & $-37 \%$ & $10 \%$ & $11 \%$ & $-2 \%$ & $1 \%$ & $11 \%$ & $18 \%$ & $10 \%$ \\
\hline
\end{tabular}

*Se excluyen de esta tabla 11 instituciones que no presentaron información sobre matrícula total y/o sobre docentes en algunos años de este periodo. 
Las celdas sombreadas corresponden al año de la certificación de autonomía en cada institución. Si una institución no presenta celda sombreada se debe a que su autonomía fue certificada con anterioridad al primer año del periodo en análisis.

Al observar las cifras año a año, se aprecia que el aumento de matrícula va, en general, acompañado de un incremento en el número de docentes y que, asimismo, en los años en que hay ascensos bruscos en el número de estudiantes, la cantidad de profesores también se eleva significativamente.

No obstante, se advierten unas pocas excepciones. En efecto, el Instituto Profesional Santo Tomás tuvo, en 2002, un aumento en su número de alumnos de $68 \%$, mientras que la cantidad de profesores se elevó sólo en $28 \%$. La Universidad Academia de Humanismo Cristiano experimentó un aumento importante de su matrícula, que alcanzó un 60\% de variación anual en 1997, no obstante su cuerpo docente se redujo en $24 \%$. La Universidad de Ciencias de la Informática aumentó su cantidad de alumnos en un 41\% en 2003 sin variar su dotación de académicos. La Universidad Mariano Egaña creció un $167 \%$ en matrícula el año 2002; sin embargo, no hubo modificaciones en su número de docentes respecto del año anterior. Empero, es posible afirmar que no se trata de tendencias, sino más bien de situaciones puntuales en ciertos años del periodo considerado.

En general, lo que se distingue en estas cifras es una evolución del tamaño de los cuadros académicos bastante consistente con la cantidad de estudiantes. Aunque en algunas instituciones la evolución del número de profesores resulta algo más errática de año en año, en los promedios del periodo se observa consistencia con el comportamiento de la matrícula. En efecto, al analizar los promedios de variación de la matrícula y del número de docentes, éstos tienden a ser bastante cercanos, con excepción de dos casos: la Universidad de Ciencias de la Informática y la Universidad de las Américas, donde el aumento en la matrícula ha sido, en términos acumulados, notoriamente mayor que el incremento de profesores. 


\subsection{La dedicación horaria de los profesores}

Pero las cifras anteriormente descritas no aportan pistas para conocer el compromiso horario que los profesores tienen con las instituciones. Ello no es trivial, pues la enseñanza conlleva funciones más allá de la docencia directa, como el tiempo para consultas de los estudiantes, horas de preparación de clases, de corrección de exámenes y trabajos; como, asimismo, actividades de investigación y extensión, entre otras. Por lo tanto, es relevante que las instituciones, en la medida que se van desarrollando, conformen equipos docentes con una dedicación horaria razonable que permita la realización adecuada de todas estas funciones.

Desde el año 2000 el CSE dispone de datos acerca de la proporción de docentes que cuentan con jornada media o mayor en cada institución.

Tabla 10. Proporción de docentes con jornada mayor o igual a media.

\begin{tabular}{lrrrrrr}
\hline & 2000 & 2001 & 2002 & 2003 & 2004 & Promedio \\
\hline INSTITUTOS PROFESIONALES & & & & & & \\
\hline AIEP & $23 \%$ & $23 \%$ & $5 \%$ & $5 \%$ & $19 \%$ & $15 \%$ \\
Carlos Casanueva & $21 \%$ & $19 \%$ & $24 \%$ & $16 \%$ & $8 \%$ & $18 \%$ \\
De Artes y Comunicación ARCOS & $6 \%$ & $6 \%$ & $5 \%$ & $5 \%$ & $6 \%$ & $6 \%$ \\
Del Valle Central & $2 \%$ & $14 \%$ & $11 \%$ & $11 \%$ & $2 \%$ & $8 \%$ \\
Diego Portales & $30 \%$ & $23 \%$ & $25 \%$ & $22 \%$ & $31 \%$ & $26 \%$ \\
EATRI & $36 \%$ & $41 \%$ & $45 \%$ & $45 \%$ & $44 \%$ & $42 \%$ \\
ESUCOMEX & $18 \%$ & $24 \%$ & $24 \%$ & $24 \%$ & $24 \%$ & $22 \%$ \\
La Araucana & $32 \%$ & $33 \%$ & $33 \%$ & $34 \%$ & $24 \%$ & $31 \%$ \\
Santo Tomás & $18 \%$ & $15 \%$ & $10 \%$ & $10 \%$ & $7 \%$ & $12 \%$ \\
\hline Promedio Institutos Profesionales & $21 \%$ & $22 \%$ & $20 \%$ & $19 \%$ & $18 \%$ & \\
\hline UNIVERSIDADES & & & & & & \\
\hline Academia de Humanismo Cristiano & $17 \%$ & $16 \%$ & $17 \%$ & $16 \%$ & $15 \%$ & $16 \%$ \\
Alberto Hurtado & $44 \%$ & $39 \%$ & $36 \%$ & $28 \%$ & $27 \%$ & $35 \%$ \\
Andrés Bello & $18 \%$ & $26 \%$ & $27 \%$ & $26 \%$ & $24 \%$ & $24 \%$ \\
Católica Silva Henríquez & $26 \%$ & $46 \%$ & $36 \%$ & $35 \%$ & $38 \%$ & $36 \%$ \\
De Arte y Ciencias Sociales ARCIS & $20 \%$ & $18 \%$ & $53 \%$ & $21 \%$ & $19 \%$ & $26 \%$ \\
De Artes, Ciencias y Comunicación & $22 \%$ & $29 \%$ & $24 \%$ & $21 \%$ & $20 \%$ & $23 \%$ \\
UNIACC & & & & & & \\
De Ciencias de la Informática & $19 \%$ & $27 \%$ & $25 \%$ & $25 \%$ & $20 \%$ & $23 \%$ \\
De Las Américas & $27 \%$ & $24 \%$ & $34 \%$ & $18 \%$ & $33 \%$ & $27 \%$ \\
De Vina del Mar & $26 \%$ & $28 \%$ & $31 \%$ & $33 \%$ & $32 \%$ & $30 \%$ \\
Del Desarrollo & $12 \%$ & $16 \%$ & $18 \%$ & $16 \%$ & $18 \%$ & $16 \%$ \\
& & & & & &
\end{tabular}




\begin{tabular}{lrrrrrr} 
Del Mar & $28 \%$ & $39 \%$ & $40 \%$ & $32 \%$ & $34 \%$ & $34 \%$ \\
Diego Portales & $14 \%$ & $29 \%$ & $24 \%$ & $37 \%$ & $20 \%$ & $25 \%$ \\
Finis Terrae & $5 \%$ & $7 \%$ & $16 \%$ & $14 \%$ & $9 \%$ & $10 \%$ \\
Iberoamericana de & $21 \%$ & $46 \%$ & $46 \%$ & $22 \%$ & $19 \%$ & $31 \%$ \\
Ciencias y Tecnología & & & & & & \\
Internacional Sek & $23 \%$ & $31 \%$ & $36 \%$ & $29 \%$ & $25 \%$ & $29 \%$ \\
La República & $14 \%$ & $14 \%$ & $16 \%$ & $15 \%$ & $13 \%$ & $14 \%$ \\
Mariano Egaña & $15 \%$ & $25 \%$ & $25 \%$ & $3 \%$ & $4 \%$ & $14 \%$ \\
Mayor & $30 \%$ & $11 \%$ & $12 \%$ & $16 \%$ & $20 \%$ & $18 \%$ \\
San Sebastián & $40 \%$ & $35 \%$ & $34 \%$ & $10 \%$ & $22 \%$ & $28 \%$ \\
Santo Tomás & $27 \%$ & $26 \%$ & $25 \%$ & $24 \%$ & $25 \%$ & $25 \%$ \\
Pérez Rosales & $27 \%$ & $29 \%$ & $29 \%$ & $35 \%$ & $39 \%$ & $32 \%$ \\
\hline Promedio Universidades & $23 \%$ & $27 \%$ & $29 \%$ & $23 \%$ & $23 \%$ & \\
\hline Promedio total porcentaje docentes & & & & & & \\
contratados por jornada media o mayor & $22 \%$ & $25 \%$ & $26 \%$ & $22 \%$ & $21 \%$ & $23 \%$ \\
\hline
\end{tabular}

Se omitieron de esta tabla cinco instituciones que no presentaron información sobre jornada de sus docentes en algunos de los años de este periodo.

Las celdas sombreadas corresponden al año de la certificación de autonomía en cada institución. Si una institución no presenta celda sombreada, se debe a que su autonomía fue certificada con anterioridad al primer año del periodo en análisis.

El primer dato que llama la atención es que este grupo de instituciones, en promedio, no ha elevado su tasa de profesores de mayor jornada en este periodo. En efecto, se distingue un leve aumento del porcentaje de docentes contratados por jornada media o mayor hasta 2002, para volver a caer levemente quedando, en 2004, un punto más abajo que en 2000. Esto es prácticamente idéntico tanto para institutos profesionales como para universidades, aun cuando estas últimas muestran porcentajes algo mayores (entre 23 y 29\%), en promedio, que el de los institutos profesionales (entre 18 y 22\%).

Los promedios de los porcentajes de profesores de media jornada o mayor de este grupo de instituciones son bastante más bajos que los que presentan todas las instituciones del país, particularmente en el caso de las universidades. En efecto, es posible indicar como referente que, conforme datos de INDICES 2005, las universidades del país mantienen en promedio un 36\% de profesores de jornada media o mayor y los institutos profesionales poco más de un $22 \%$ de docentes con esa dedicación horaria. 
Ahora bien, analizando la evolución de este indicador en el caso de cada una de las instituciones de este estudio, se observa que hay un grupo de instituciones que mantienen una proporción de profesores de jornada relativamente regular en este periodo, mientras otras muestran un comportamiento algo más errático. El Instituto Profesional AIEP reduce su cuerpo de académicos con jornada media o mayor a un $5 \%$ en 2002 , después de haber mantenido una proporción de 23\%, y en 2004 remonta hasta un 19\%. El Instituto Profesional del Valle Central empieza el periodo con un 2\% de profesores de jornada media o mayor, luego aumenta a cifras cercanas al 20\% y en 2004 cae de nuevo a 2\%. La Universidad Finis Terrae pasa de un $7 \%$ en 2001 a un $16 \%$ el año siguiente y baja a $9 \%$ en 2004. La Universidad Mayor mantenía en 2000 un 30\% de docentes de jornada media o mayor, para reducirlos en 2001 a 11\% y después aumentarlo paulatinamente hasta alcanzar en 2004 un 20\%. La Universidad San Sebastián inicia el periodo con proporciones cercanas al 30\%, las que en 2003 se reducen al 10\%.

Además, resulta significativo que en 2002 algunas instituciones aumenten considerablemente este porcentaje para después volver a descender llegando a los niveles presentados en años anteriores. Estos aumentos repentinos distorsionan el promedio de este grupo de instituciones en ese año, el que alcanza un $26 \%$, por lo que, aislando esos casos, dicho promedio sería algunos puntos menor.

En términos generales, es posible afirmar que, con excepción del Instituto Profesional EATRI, las universidades Católica Silva Henríquez, De Viña del Mar, Del Desarrollo, Del Mar y Pérez Rosales, las instituciones no han ido aumentando de manera regular su porcentaje de profesores con mayor dedicación horaria, en este periodo.

Esto no quiere decir que las instituciones no hayan aumentado sus profesores de media jornada o mayor, pues si el porcentaje se ha mantenido constante y las plantas de profesores se han ampliado, como pudo verse en las cifras del número de académicos, la cantidad 
de docentes con contrato de jornada media o mayor se ha elevado algo en términos absolutos. No obstante, ello implica que ha aumentado también el número absoluto de profesores contratados por horas. No se aprecia, por lo tanto, una intención, traducida en alguna tendencia, de aumentar la proporción de profesores de mayor dedicación al interior de la mayoría de las instituciones, de modo que éstos puedan, como ya se señaló, cumplir con las funciones que van más allá de la docencia directa.

\subsection{El nivel de formación de los docentes}

La preparación de los profesores también es central en la efectividad del proceso de enseñanza-aprendizaje. Una manera de explorar esta variable es examinar el porcentaje del cuerpo académico que cuenta con estudios de posgrado. Se consideran como tales los estudios emprendidos tras la obtención de un primer grado de licenciatura, los que culminan en un nuevo grado académico de mayor nivel, como magíster y doctor. Sobre aquello, hay datos sistemáticos desde el 2000 hasta el año pasado.

Tabla 11: Porcentaje de docentes con estudios de posgrado.

\begin{tabular}{lrrrrrr}
\hline Nombre & 2000 & 2001 & 2002 & 2003 & 2004 & Promedio \\
\hline INSTITUTOS PROFESIONALES & & & & & & \\
\hline AIEP & $7 \%$ & $9 \%$ & $10 \%$ & $3 \%$ & $4 \%$ & $7 \%$ \\
Carlos Casanueva & $5 \%$ & $7 \%$ & $6 \%$ & $9 \%$ & $6 \%$ & $7 \%$ \\
De Artes y Comunicación ARCOS & $5 \%$ & $4 \%$ & $4 \%$ & $4 \%$ & $3 \%$ & $4 \%$ \\
Del Valle Central & $6 \%$ & $13 \%$ & $11 \%$ & $11 \%$ & $13 \%$ & $11 \%$ \\
Diego Portales & $9 \%$ & $8 \%$ & $12 \%$ & $12 \%$ & $10 \%$ & $10 \%$ \\
EATRI & $12 \%$ & $11 \%$ & $18 \%$ & $18 \%$ & $13 \%$ & $14 \%$ \\
ESUCOMEX & $8 \%$ & $19 \%$ & $19 \%$ & $19 \%$ & $19 \%$ & $17 \%$ \\
La Araucana & $15 \%$ & $18 \%$ & $17 \%$ & $15 \%$ & $26 \%$ & $18 \%$ \\
Santo Tomás & $11 \%$ & $14 \%$ & $6 \%$ & $11 \%$ & $9 \%$ & $10 \%$ \\
\hline Promedio institutos profesionales & $9 \%$ & $12 \%$ & $12 \%$ & $11 \%$ & $11 \%$ & \\
\hline UNIVERSIDADES & & & & & & \\
\hline Academia de Humanismo Cristiano & $39 \%$ & $50 \%$ & $35 \%$ & $48 \%$ & $46 \%$ & $44 \%$ \\
Alberto Hurtado & $65 \%$ & $78 \%$ & $71 \%$ & $78 \%$ & $71 \%$ & $72 \%$ \\
Andrés Bello & $34 \%$ & $29 \%$ & $33 \%$ & $31 \%$ & $32 \%$ & $32 \%$ \\
Católica Silva Henríquez & $26 \%$ & $37 \%$ & $29 \%$ & $36 \%$ & $41 \%$ & $34 \%$ \\
De Arte y Ciencias Sociales ARCIS & $15 \%$ & $17 \%$ & $18 \%$ & $29 \%$ & $28 \%$ & $21 \%$ \\
De Artes, Ciencias y Comunicación & $23 \%$ & $22 \%$ & $26 \%$ & $28 \%$ & $37 \%$ & $27 \%$
\end{tabular}

UNIACC 


\begin{tabular}{lllllll} 
De Ciencias de la Informática & $30 \%$ & $33 \%$ & $38 \%$ & $35 \%$ & $31 \%$ & $33 \%$ \\
De Las Américas & $32 \%$ & $31 \%$ & $29 \%$ & $29 \%$ & $28 \%$ & $30 \%$ \\
De Viña del Mar & $18 \%$ & $21 \%$ & $23 \%$ & $12 \%$ & $18 \%$ & $18 \%$ \\
Del Desarrollo & $34 \%$ & $35 \%$ & $37 \%$ & $41 \%$ & $49 \%$ & $39 \%$ \\
Del Mar & $40 \%$ & $47 \%$ & $48 \%$ & $38 \%$ & $48 \%$ & $44 \%$ \\
Diego Portales & $26 \%$ & $41 \%$ & $47 \%$ & $42 \%$ & $35 \%$ & $38 \%$ \\
Finis Terrae & $26 \%$ & $24 \%$ & $34 \%$ & $36 \%$ & $31 \%$ & $30 \%$ \\
Iberoamericana de Ciencias & $35 \%$ & $47 \%$ & $47 \%$ & $41 \%$ & $35 \%$ & $41 \%$ \\
y Tecnología & & & & & & \\
Internacional Sek & $30 \%$ & $34 \%$ & $32 \%$ & $29 \%$ & $24 \%$ & $30 \%$ \\
La República & $16 \%$ & $21 \%$ & $19 \%$ & $19 \%$ & $18 \%$ & $18 \%$ \\
Mariano Egaña & $46 \%$ & $16 \%$ & $16 \%$ & $46 \%$ & $46 \%$ & $34 \%$ \\
Mayor & $39 \%$ & $23 \%$ & $27 \%$ & $29 \%$ & $31 \%$ & $30 \%$ \\
San Sebastián & $32 \%$ & $27 \%$ & $27 \%$ & $17 \%$ & $22 \%$ & $25 \%$ \\
Santo Tomás & $23 \%$ & $26 \%$ & $33 \%$ & $34 \%$ & $31 \%$ & $29 \%$ \\
Pérez Rosales & $25 \%$ & $24 \%$ & $24 \%$ & $26 \%$ & $22 \%$ & $24 \%$ \\
\hline Promedio Universidades & $31 \%$ & $33 \%$ & $33 \%$ & $34 \%$ & $34 \%$ & \\
\hline Promedio total porcentaje docentes & & & & & & \\
con estudios de posgrado & $24 \%$ & $25 \%$ & $26 \%$ & $27 \%$ & $27 \%$ & $26 \%$ \\
\hline
\end{tabular}

* Se omitieron de esta tabla cinco instituciones que no presentaron información sobre docentes con posgrado en algunos de los años de este periodo.

Las celdas sombreadas corresponden al año de la certificación de autonomía en cada institución. Si una institución no presenta celda sombreada se debe a que su autonomía fue certificada con anterioridad al primer año del periodo en análisis.

Este grupo de instituciones alcanza entre 31 y $34 \%$ de profesores con estudios de posgrado en el caso de las universidades y entre 9 y 12\% para los institutos profesionales, observándose una distancia considerable entre los dos tipos de instituciones. Estas cifras son, en ambos casos, significativamente más bajas que las proporciones que mantienen las instituciones del país en general. Efectivamente, las universidades que funcionaban en el país hasta 2004 presentaban un promedio que superaba el 38\% de docentes con estudios de posgrado y los institutos profesionales en el mismo año mostraron un promedio de poco más de $20 \%$ de académicos con ese nivel de formación.

En relación con el grupo, se aprecia en las instituciones analizadas en este estudio un leve aumento del porcentaje de profesores con posgrado; no obstante, la evolución individual de 
este indicador pone en evidencia varias diferencias entre las instituciones. De ellas, alrededor de 13 instituciones mantienen relativamente constante su proporción de profesores con posgrado; cerca de diez aumentan su dotación de docentes posgraduados; sólo dos de ellas la reducen; y seis muestran una evolución notoriamente errática. Es destacable que varias instituciones presenten en el tiempo un incremento de sus profesores de mayor calificación; sin embargo, llama la atención que un número no menor de instituciones presenten un comportamiento irregular y que otras pocas tengan una dotación descendente de académicos con posgrado, lo que levanta la pregunta por las políticas de selección y de perfeccionamiento docente, así como de rotación y permanencia de profesores, que existe al interior de las instituciones.

\subsection{Comportamiento general de los indicadores de docencia} Las cifras agrupadas en esta sección muestran que las instituciones han ido aumentando su dotación de académicos en la medida que crece la matrícula, aunque no siempre en una proporción similar. Asimismo, los incrementos repentinos del número de alumnos, que en muchas ocasiones se dan en los años siguientes a la certificación de autonomía, son normalmente acompañados por aumentos significativos en la cantidad de profesores, salvo contadas excepciones.

Sin perjuicio de ello, no se identificaron tendencias tan claras al revisar la dedicación horaria de los docentes, donde, además de constatar una alta proporción de profesores-hora en todas las instituciones, se observó una tendencia a mantener relativamente constante el porcentaje de académicos de jornada media o mayor, observándose incluso varias instituciones que redujeron este porcentaje y algunas que mostraron una evolución irregular en ello. Esto significa que el número de docentes con jornada media o mayor se ha incrementado algo en términos absolutos, pues el universo de profesores es mayor, pero también lo ha hecho entonces el número de profesores-hora. 
Una situación similar se vio en las cifras relativas al nivel de calificación de los profesores, donde la tendencia del grupo de instituciones fue de un aumento muy leve de docentes con posgrado, explicado principalmente por unas pocas instituciones que presentan un aumento considerable y varias que mantienen la cifra relativamente constante.

En consecuencia, si bien el número de profesores contratados por estas instituciones ha crecido, algunas de las condiciones para la función docente no muestran mayores cambios. Ello, aun cuando varias de estas instituciones se encuentran ya en una etapa avanzada de desarrollo y en un proceso acelerado de crecimiento, y debieran reunir las condiciones para ir conformando equipos docentes estables y de mayor dedicación. En ese sentido, la irregularidad observada en muchas de estas cifras interroga sobre la capacidad de las instituciones de conformar núcleos docentes que conduzcan los procesos formativos con una relativa continuidad, por lo que será interesante investigar a futuro cómo está operando la carrera académica al interior de las instituciones y los mecanismos de permanencia, jerarquización, promoción y rotación de profesores; en otras palabras, develar qué ocurre con los equipos académicos de las instituciones.

\section{Evolución de los recursos bibliográficos}

Para llevar a cabo un adecuado proceso de enseñanza-aprendizaje, los recursos educacionales de que dispone una institución juegan un papel preponderante. Dentro de ello, los recursos bibliográficos a los que tiene acceso el estudiante deben ser suficientes en cantidad y calidad para apoyar sus estudios y complementar su aprendizaje. Ello implica que, por ejemplo, si la matrícula institucional se incrementa, el número de copias de la biblioteca debiera aumentar, o que, si se inician nuevos programas académicos, debiera haber una adquisición de textos para las nuevas asignaturas. 


\subsection{Los volúmenes de biblioteca}

Por "volumen de biblioteca" se entiende el número de libros completos del mismo título. En otras palabras, se trata de las existencias bibliográficas. Así, una biblioteca suele tener más de un volumen del mismo título, en función del número de alumnos.

A continuación, se analiza el desarrollo de los recursos bibliográficos de las instituciones en términos del número de volúmenes disponibles en sus bibliotecas, con el fin de compararlo con la matrícula institucional.

Tabla 12: Variación anual de matrícula y cantidad de volúmenes de biblioteca.

\begin{tabular}{|c|c|c|c|c|c|c|c|c|c|c|}
\hline \multirow{2}{*}{\multicolumn{2}{|c|}{ INSTITUTOS PROFESIONALES }} & \multirow[t]{2}{*}{1997} & \multirow[t]{2}{*}{1998} & \multirow[t]{2}{*}{1999} & \multirow[t]{2}{*}{2000} & \multirow[t]{2}{*}{2001} & \multirow[t]{2}{*}{2002} & \multirow[t]{2}{*}{2003} & \multicolumn{2}{|c|}{ 2004Promedio } \\
\hline & & & & & & & & & & \\
\hline \multirow[t]{2}{*}{ Carlos Casanueva } & Matrícula & $9 \%$ & $-1 \%$ & $6 \%$ & $10 \%$ & $17 \%$ & $13 \%$ & $26 \%$ & $-3 \%$ & $10 \%$ \\
\hline & Volúmenes & $65 \%$ & $20 \%$ & $34 \%$ & $3 \%$ & $12 \%$ & $23 \%$ & $-12 \%$ & $5 \%$ & $19 \%$ \\
\hline \multirow[t]{2}{*}{ Diego Portales } & Matrícula & $1 \%$ & $-1 \%$ & $5 \%$ & $10 \%$ & $3 \%$ & $141 \%$ & $39 \%$ & $-6 \%$ & $24 \%$ \\
\hline & Volúmenes & $0 \%$ & $3 \%$ & $10 \%$ & $34 \%$ & $9 \%$ & $63 \%$ & $10 \%$ & $4,7 \%$ & $17 \%$ \\
\hline \multirow[t]{2}{*}{ EATRI } & Matrícula & $20 \%$ & $20 \%$ & $-11 \%$ & $-19 \%$ & $3 \%$ & $-5 \%$ & $2 \%$ & $31 \%$ & $5 \%$ \\
\hline & Volúmenes & $-18 \%$ & $-12 \%$ & $19 \%$ & $4 \%$ & $6 \%$ & $3 \%$ & $4 \%$ & $4 \%$ & $1 \%$ \\
\hline \multirow[t]{2}{*}{ Santo Tomás } & Matrícula & $8 \%$ & $-3 \%$ & $0 \%$ & $1 \%$ & $-4 \%$ & $68 \%$ & $11 \%$ & $0 \%$ & $10 \%$ \\
\hline & Volúmenes & $29 \%$ & $-5 \%$ & $10 \%$ & $35 \%$ & $-10 \%$ & $29 \%$ & $18 \%$ & $108 \%$ & $27 \%$ \\
\hline \multicolumn{11}{|l|}{ UNIVERSIDADES } \\
\hline Academia de & Matrícula & $60 \%$ & $1 \%$ & $8 \%$ & $19 \%$ & $16 \%$ & $14 \%$ & $6 \%$ & $5 \%$ & $16 \%$ \\
\hline Humanismo Cristiano & Volúmenes & $256 \%$ & $12 \%$ & $109 \%$ & $21 \%$ & $-43 \%$ & $41 \%$ & $100 \%$ & $14 \%$ & $64 \%$ \\
\hline \multirow[t]{2}{*}{ Alberto Hurtado } & Matrícula & & & $88 \%$ & $170 \%$ & $7 \%$ & $50 \%$ & $38 \%$ & $25 \%$ & $63 \%$ \\
\hline & Volúmenes & & & $173 \%$ & $-30 \%$ & $-4 \%$ & $9 \%$ & $49 \%$ & $6 \%$ & $34 \%$ \\
\hline \multirow[t]{2}{*}{ Andrés Bello } & Matrícula & $0 \%$ & $0 \%$ & $3 \%$ & $66 \%$ & $6 \%$ & $23 \%$ & $4 \%$ & $13 \%$ & $14 \%$ \\
\hline & Volúmenes & $10 \%$ & $24 \%$ & $13 \%$ & $70 \%$ & $19 \%$ & $17 \%$ & $7 \%$ & $31 \%$ & $24 \%$ \\
\hline \multirow[t]{2}{*}{ Autónoma del Sur } & Matrícula & $29 \%$ & $-22 \%$ & $104 \%$ & $0 \%$ & $-4 \%$ & $9 \%$ & $155 \%$ & $24 \%$ & $37 \%$ \\
\hline & Volúmenes & $36 \%$ & $16 \%$ & $18 \%$ & $131 \%$ & $3 \%$ & $8 \%$ & $67 \%$ & $4 \%$ & $35 \%$ \\
\hline \multirow[t]{2}{*}{ Católica Silva Henríquez } & Matrícula & $11 \%$ & $-3 \%$ & $-4 \%$ & $-2 \%$ & $-5 \%$ & $-1 \%$ & $-1 \%$ & $6 \%$ & $0 \%$ \\
\hline & Volúmenes & $16 \%$ & $13 \%$ & $6 \%$ & $15 \%$ & $4 \%$ & $9 \%$ & $6 \%$ & $12 \%$ & $10 \%$ \\
\hline \multirow[t]{2}{*}{ Central de Chile } & Matrícula & $4 \%$ & $-4 \%$ & $5 \%$ & $-3 \%$ & $-16 \%$ & $22 \%$ & $1 \%$ & $-7 \%$ & $0 \%$ \\
\hline & Volúmenes & $31 \%$ & $1 \%$ & $6 \%$ & $14 \%$ & $12 \%$ & $20 \%$ & $-5 \%$ & $-16 \%$ & $8 \%$ \\
\hline y Ciencias & Matrícula & $-2 \%$ & $13 \%$ & $4 \%$ & $9 \%$ & $48 \%$ & $-1 \%$ & $9 \%$ & $-5 \%$ & $9 \%$ \\
\hline Sociales ARCIS & Volúmenes & $-3 \%$ & $-4 \%$ & $46 \%$ & $34 \%$ & $30 \%$ & $-97 \% *$ & $4.199 \% *$ & $14, \%$ & \\
\hline De Artes, Ciencias y & Matrícula & $8 \%$ & $12 \%$ & $2 \%$ & $24 \%$ & $8 \%$ & $13 \%$ & $12 \%$ & $7 \%$ & $11 \%$ \\
\hline Comunicación UNIACC & Volúmenes & $31 \%$ & $15 \%$ & $9 \%$ & $47 \%$ & $4 \%$ & $51 \%$ & $14 \%$ & $5 \%$ & $22 \%$ \\
\hline De Ciencias de & Matrícula & $29 \%$ & $13 \%$ & $21 \%$ & $14 \%$ & $7 \%$ & $-15 \%$ & $41 \%$ & $3 \%$ & $14 \%$ \\
\hline la Informática & Volúmenes & $45 \%$ & $22 \%$ & $123 \%$ & $20 \%$ & $39 \%$ & $15 \%$ & $19 \%$ & $8 \%$ & $36 \%$ \\
\hline \multirow[t]{2}{*}{ Del Desarrollo } & Matrícula & $19 \%$ & $7 \%$ & $81 \%$ & $22 \%$ & $16 \%$ & $3 \%$ & $-12 \%$ & $-5 \%$ & $22 \%$ \\
\hline & Volúmenes & $27 \%$ & $12 \%$ & $116 \%$ & $7 \%$ & $18 \%$ & $17 \%$ & $9 \%$ & $13 \%$ & $27 \%$ \\
\hline \multirow[t]{2}{*}{ Del Mar } & Matrícula & $22 \%$ & $4 \%$ & $16 \%$ & $0 \%$ & $0 \%$ & $10 \%$ & $112 \%$ & $41 \%$ & $26 \%$ \\
\hline & Volúmenes & $112 \%$ & $28 \%$ & $9 \%$ & $7 \%$ & $4 \%$ & $14 \%$ & $56 \%$ & $83 \%$ & $39 \%$ \\
\hline \multirow[t]{2}{*}{ Diego Portales } & Matrícula & $1 \%$ & $11 \%$ & $0 \%$ & $4 \%$ & $0 \%$ & $-10 \%$ & $24 \%$ & $-5 \%$ & $3 \%$ \\
\hline & Volúmenes & $13 \%$ & $-9 \%$ & $11 \%$ & $32 \%$ & $0 \%$ & $4 \%$ & $32 \%$ & $1 \%$ & $10 \%$ \\
\hline
\end{tabular}




\begin{tabular}{|c|c|c|c|c|c|c|c|c|c|c|}
\hline \multirow[t]{2}{*}{ Finis Terrae } & Matrícula & $12 \%$ & $10 \%$ & $-3 \%$ & $29 \%$ & $-11 \%$ & $13 \%$ & $0 \%$ & $10 \%$ & $7 \%$ \\
\hline & Volúmenes & $14 \%$ & $-4 \%$ & $23 \%$ & $3 \%$ & $-6 \%$ & $46 \%$ & $-28 \%$ & $23 \%$ & \\
\hline Iberoamericana de & Matrícula & $4 \%$ & $-2 \%$ & $0 \%$ & $0 \%$ & $0 \%$ & $-3 \%$ & $-6 \%$ & $-12 \%$ & \\
\hline Ciencias y Tecnología & Volúmenes & $-4 \%$ & $81 \%$ & $11 \%$ & $21 \%$ & $281 \%$ & $3 \%$ & $5 \%$ & $2 \%$ & \\
\hline \multirow[t]{2}{*}{ Internacional Sek } & Matrícula & $-12 \%$ & $3 \%$ & $10 \%$ & $-1 \%$ & $2 \%$ & $2 \%$ & $1 \%$ & $-15 \%$ & \\
\hline & Volúmenes & $-33 \%$ & $14 \%$ & $11 \%$ & $20 \%$ & $25 \%$ & $29 \%$ & $-98 \% *$ & $.419 \% *$ & \\
\hline \multirow[t]{2}{*}{ La República } & Matrícula & $6 \%$ & $3 \%$ & $16 \%$ & $-1 \%$ & $10 \%$ & $17 \%$ & $11 \%$ & $11 \%$ & \\
\hline & Volúmenes & $14 \%$ & $11 \%$ & $13 \%$ & $2 \%$ & $23 \%$ & $9 \%$ & $28 \%$ & $27 \%$ & 16 \\
\hline \multirow[t]{2}{*}{ Mariano Egaña } & Matrícula & $-3 \%$ & $-4 \%$ & $-14 \%$ & $2 \%$ & $-11 \%$ & $167 \%$ & $6 \%$ & $1 \%$ & 18 \\
\hline & Volúmenes & $14 \%$ & $11 \%$ & $4 \%$ & $7 \%$ & $11 \%$ & $23 \%$ & $64 \%$ & $71 \%$ & \\
\hline \multirow[t]{2}{*}{ Mayor } & Matrícula & $13 \%$ & $11 \%$ & $32 \%$ & $41 \%$ & $10 \%$ & $22 \%$ & $15 \%$ & $25 \%$ & 21 \\
\hline & Volúmenes & $27 \%$ & $15 \%$ & $24 \%$ & $50 \%$ & $34 \%$ & $25 \%$ & $22 \%$ & $8 \%$ & 26 \\
\hline \multirow[t]{2}{*}{ San Sebastián } & Matrícula & $5 \%$ & $8 \%$ & $8 \%$ & $6 \%$ & $24 \%$ & $44 \%$ & $69 \%$ & $22 \%$ & \\
\hline & Volúmenes & $13 \%$ & $22 \%$ & $11 \%$ & $5 \%$ & $23 \%$ & $25 \%$ & $55 \%$ & $54 \%$ & 26 \\
\hline \multirow[t]{2}{*}{ Santo Tomás } & Matrícula & $31 \%$ & $13 \%$ & $3 \%$ & $8 \%$ & $-12 \%$ & $0 \%$ & $-1 \%$ & $73 \%$ & 14 \\
\hline & Volúmenes & $27 \%$ & $21 \%$ & $14 \%$ & $24 \%$ & $18 \%$ & $14 \%$ & $15 \%$ & $13 \%$ & 18 \\
\hline \multirow[t]{2}{*}{ Pérez Rosales } & Matrícula & $6 \%$ & $7 \%$ & $0 \%$ & $11 \%$ & $4 \%$ & $-3 \%$ & $-5 \%$ & $12 \%$ & \\
\hline & Volúmenes & $0 \%$ & $198 \%$ & $6 \%$ & $7 \%$ & $7 \%$ & $-5 \%$ & $14 \%$ & $15 \%$ & 31 \\
\hline
\end{tabular}

* Se omitieron de esta tabla diez instituciones que no presentaron información sobre matrícula y/o volúmenes de biblioteca en algunos de los años de este periodo.

Las celdas sombreadas corresponden al año de la certificación de autonomía en cada institución. Si una institución no presenta celda sombreada, se debe a que su autonomía fue certificada con anterioridad al primer año del periodo en análisis.

Se han destacado con un asterisco aquellas cifras que contienen errores y que distorsionan las variaciones y los promedios de las instituciones, por lo que no se consideraron en el análisis.

Los promedios de crecimiento de cada institución muestran, en términos generales, un aumento del número de volúmenes de biblioteca superior al de la matrícula, o bien un incremento similar, con excepción del Instituto Profesional Diego Portales y de la Universidad Alberto Hurtado ${ }^{6}$.

\section{Sin embargo, tales promedios muestran una alta desviación} estándar, lo que indica que las cifras que explican los promedios tienen una alta variabilidad entre un año y otro del periodo. En efecto, al examinar la evolución de la cantidad de volúmenes de

6 Cabe precisar que la biblioteca con que cuenta la Universidad Alberto Hurtado constituye un caso particular, dado que ella recibió importantes donaciones durante los primeros años de funcionamiento por parte de la institución fundadora, lo que la convirtió en una de las mayores bibliotecas entre las universidades privadas y la mayor entre las 35 instituciones analizadas en este estudio. Por lo tanto, al referirnos a esta universidad estamos hablando de magnitudes diferentes a las observadas en las bibliotecas del resto de las instituciones. 
biblioteca año a año, se aprecia que el comportamiento es errático. Si bien en todas las instituciones la tendencia es hacia un aumento en el número de volúmenes, este incremento no suele ser sistemático en el tiempo, alternándose cifras positivas de variación anual con cifras negativas en algunos años, sin que ello encuentre siempre explicación en el comportamiento de la matrícula. Normalmente, en los años en que se aprecian aumentos drásticos en el número de alumnos, se distinguen, asimismo, incrementos de los volúmenes de biblioteca, aunque rara vez este último en una proporción similar o cercana a la de la matrícula.

En efecto, el Instituto Profesional Diego Portales, por ejemplo, sufrió un aumento de $141 \%$ en su matrícula entre 2001 y 2002, y elevó su cantidad de volúmenes de biblioteca en un 63\%, cifra superior al crecimiento histórico, pero lejana al comportamiento de la matrícula. Entre los mismos años, el Instituto Profesional Santo Tomás incrementó su matrícula en un $68 \%$, mientras que el número de volúmenes disponibles se mantuvo cercano al promedio, sin que éstos aumentaran en mayor medida el año posterior. No obstante, dos años después la cantidad de volúmenes creció en un $108 \%$, mientras su matrícula se mantuvo constante. La Universidad Alberto Hurtado creció en los años 1999 y 2000 un 88 y 170\% respectivamente, en términos de su número de estudiantes. Los volúmenes bibliográficos disponibles crecieron significativamente en 1999, alcanzando una variación de $173 \%$, a pesar de que en 2002 se redujeron en un 30\%. La Universidad del Mar aumentó su número de alumnos en $112 \%$ en 2003, incrementando su cantidad de volúmenes de biblioteca sólo en 56\%. En 2002 la Universidad Mariano Egaña elevó su matrícula en $167 \%$ y aumentó sus volúmenes bibliográficos en $23 \%$.

Asimismo, se observan casos en que los volúmenes aumentan de un año al siguiente de manera desmedida y sin correspondencia con el número de alumnos. Así ocurre, por ejemplo, con la Universidad Academia de Humanismo Cristiano en los años 1999 y 2003, en los que el incremento de la matrícula no supera el 10\%; 
sin embargo, el aumento de los volúmenes supera el 100\%. Del mismo modo, la Universidad de Ciencias de la Informática elevó sus volúmenes de biblioteca en $123 \%$ en 1999, aun cuando su matrícula aumentó sólo en $21 \%$. Igualmente, la Universidad Iberoamericana de Ciencias y Tecnología tuvo un aumento de volúmenes en 2001 de $281 \%$, mientras su matrícula se mantuvo igual al año anterior. Asimismo, en la Universidad Pérez Rosales la cantidad de alumnos en el año 1998 se incrementó sólo en un 7\%, en circunstancias que su número de volúmenes aumentó en 198\%.

Es posible que estas situaciones de crecimiento de los volúmenes de biblioteca en promedio superior al de la matrícula institucional responda a que, en algunos casos, las colecciones bibliográficas no se encuentran en estado de régimen, por lo que requieren incrementarse a fin de cubrir la bibliografía de todas las nuevas asignaturas. En todo caso, si bien una evolución de este tipo parece, en principio, positiva para efectos del proceso de enseñanza-aprendizaje, resulta llamativo que, en general, el comportamiento de esa variable no sea sistemático ni coherente con la evolución de la matrícula.

\subsection{Los títulos de biblioteca}

Se entiende como "títulos" el número de títulos de libros completos (originales) que posee la biblioteca de una sede. Por libro completo se entiende uno que comprenda todos y cada uno de los capítulos del mismo, y que se encuentre debidamente empastado. De esta forma, el anillado de algunos capítulos de un libro no corresponde al concepto de libro completo.

La siguiente tabla muestra la evolución del número de títulos disponibles en biblioteca, en comparación con el número de carreras impartidas cada año entre 1997 y 2004, en términos de la variación anual experimentada. 
Tabla 13: Variación anual del número de carreras y cantidad de títulos de biblioteca.

\begin{tabular}{|c|c|c|c|c|c|c|c|c|c|c|}
\hline \multirow{2}{*}{\multicolumn{2}{|c|}{ INSTITUTOS PROFESIONALES }} & \multirow[t]{2}{*}{1997} & \multirow[t]{2}{*}{1998} & \multirow[t]{2}{*}{1999} & \multirow[t]{2}{*}{2000} & \multirow[t]{2}{*}{2001} & \multirow[t]{2}{*}{2002} & \multirow[t]{2}{*}{2003} & \multicolumn{2}{|c|}{2004 Promedio } \\
\hline & & & & & & & & & & \\
\hline \multirow[t]{2}{*}{ Carlos Casanueva } & Carreras & $0 \%$ & $0 \%$ & $0 \%$ & $0 \%$ & $50 \%$ & $67 \%$ & $0 \%$ & $40 \%$ & $20 \%$ \\
\hline & Títulos & $35 \%$ & $8 \%$ & $48 \%$ & $3 \%$ & $3 \%$ & $29 \%$ & $-4 \%$ & $-47 \%$ & $9 \%$ \\
\hline \multirow[t]{2}{*}{ Diego Portales } & Carreras & $0 \%$ & $0 \%$ & $0 \%$ & $-22 \%$ & $57 \%$ & $491 \%$ & $-9 \%$ & $27 \%$ & $68 \%$ \\
\hline & Títulos & $0 \%$ & $15 \%$ & $7 \%$ & $23 \%$ & $7 \%$ & $117 \%$ & $3 \%$ & $11 \%$ & $23 \%$ \\
\hline \multirow[t]{2}{*}{ EATRI } & Carreras & $0 \%$ & $100 \%$ & $0 \%$ & $250 \%$ & $0 \%$ & $0 \%$ & $71 \%$ & $-25 \%$ & $50 \%$ \\
\hline & Títulos & $-11 \%$ & $-5 \%$ & $9 \%$ & $4 \%$ & $3 \%$ & $2 \%$ & $2 \%$ & $3 \%$ & $1 \%$ \\
\hline \multirow[t]{2}{*}{ Santo Tomás } & Carreras & $0 \%$ & $0 \%$ & $0 \%$ & $175 \%$ & $118 \%$ & $63 \%$ & $38 \%$ & $2 \%$ & $49 \%$ \\
\hline & Títulos & $29 \%$ & $-1 \%$ & $-10 \%$ & $53 \%$ & $-15 \%$ & $28 \%$ & $14 \%$ & $123 \%$ & $28 \%$ \\
\hline \multicolumn{11}{|l|}{ UNIVERSIDADES } \\
\hline \multicolumn{11}{|l|}{ Academia de } \\
\hline \multirow[t]{2}{*}{ Humanismo Cristiano } & Carrera & $33 \%$ & $0 \%$ & $0 \%$ & $17 \%$ & $36 \%$ & $0 \%$ & $5 \%$ & $5 \%$ & $12 \%$ \\
\hline & Títulos & $319 \%$ & $15 \%$ & $73 \%$ & $8 \%$ & $-50 \%$ & $24 \%$ & $9 \%$ & $8 \%$ & $61 \%$ \\
\hline \multirow[t]{2}{*}{ Alberto Hurtado } & Carreras & & & $0 \%$ & $0 \%$ & $133 \%$ & $29 \%$ & $11 \%$ & $10 \%$ & $35 \%$ \\
\hline & Títulos & & & $18 \%$ & $-28 \%$ & $66 \%$ & $9 \%$ & $48 \%$ & $5 \%$ & $20 \%$ \\
\hline \multirow[t]{2}{*}{ Andrés Bello } & Carreras & $8 \%$ & $23 \%$ & $0 \%$ & $156 \%$ & $37 \%$ & $5 \%$ & $8 \%$ & $34 \%$ & $34 \%$ \\
\hline & Títulos & $19 \%$ & $24 \%$ & $15 \%$ & $68 \%$ & $42 \%$ & $2 \%$ & $36 \%$ & $4 \%$ & $26 \%$ \\
\hline Católica Silva & Carreras & $0 \%$ & $0 \%$ & $0 \%$ & $24 \%$ & $38 \%$ & $-3 \%$ & $-14 \%$ & $-29 \%$ & $2 \%$ \\
\hline Henríquez & Títulos & $15 \%$ & $5 \%$ & $9 \%$ & $14 \%$ & $9 \%$ & $3 \%$ & $1 \%$ & $10 \%$ & $8 \%$ \\
\hline \multirow[t]{2}{*}{ Central de Chile } & Carreras & $0 \%$ & $0 \%$ & $7 \%$ & $7 \%$ & $19 \%$ & $5 \%$ & $70 \%$ & $6 \%$ & $14 \%$ \\
\hline & Títulos & $8 \%$ & $15 \%$ & $12 \%$ & $15 \%$ & $16 \%$ & $7 \%$ & $8 \%$ & $-15 \%$ & $8 \%$ \\
\hline e Arte y Ciencias & Carreras & $0 \%$ & $0 \%$ & $0 \%$ & $38 \%$ & $22 \%$ & $41 \%$ & $100 \%$ & $-29 \%$ & $22 \%$ \\
\hline Sociales ARCIS & Títulos & $3 \%$ & $7 \%$ & $22 \%$ & $-4 \%$ & $25 \%$ & $-95 \% *$ & $2.474 \%$ * & $48 \%$ & \\
\hline De Artes, Ciencias y & Carreras & $0 \%$ & $10 \%$ & $9 \%$ & $-17 \%$ & $20 \%$ & $-8 \%$ & $0 \%$ & $64 \%$ & $10 \%$ \\
\hline Comunicación UNIACC & Títulos & $40 \%$ & $19 \%$ & $6 \%$ & $27 \%$ & $20 \%$ & $62 \%$ & $13 \%$ & $3 \%$ & $24 \%$ \\
\hline De Ciencias de & Carreras & $0 \%$ & $0 \%$ & $0 \%$ & $75 \%$ & $14 \%$ & $-13 \%$ & $86 \%$ & $23 \%$ & $23 \%$ \\
\hline la Informática & Títulos & $44 \%$ & $17 \%$ & $51 \%$ & $15 \%$ & $30 \%$ & $5 \%$ & $35 \%$ & $5 \%$ & $25 \%$ \\
\hline Del Desarrollo & Carreras & $-13 \%$ & $14 \%$ & $13 \%$ & $78 \%$ & $38 \%$ & $18 \%$ & $4 \%$ & $11 \%$ & $20 \%$ \\
\hline & Títulos & $44 \%$ & $17 \%$ & $164 \%$ & $-1 \%$ & $13 \%$ & $12 \%$ & $7 \%$ & $6 \%$ & $33 \%$ \\
\hline Del Mar & Carreras & $25 \%$ & $-13 \%$ & $15 \%$ & $47 \%$ & $23 \%$ & $285 \%$ & $137 \%$ & $-17 \%$ & $63 \%$ \\
\hline & Títul & $-21 \%$ & $38 \%$ & $10 \%$ & $12 \%$ & $16 \%$ & $13 \%$ & $79 \%$ & $40 \%$ & $23 \%$ \\
\hline Diego Portales & Carreras & $-9 \%$ & $10 \%$ & $0 \%$ & $73 \%$ & $126 \%$ & $-9 \%$ & $-23 \%$ & $-7 \%$ & $20 \%$ \\
\hline & Títulos & $12 \%$ & $12 \%$ & $-9 \%$ & $43 \%$ & $3 \%$ & $0 \%$ & $-10 \%$ & $6 \%$ & $7 \%$ \\
\hline Finis Terrae & Carreras & $0 \%$ & $14 \%$ & $13 \%$ & $22 \%$ & $36 \%$ & $20 \%$ & $22 \%$ & $-14 \%$ & $14 \%$ \\
\hline & Títulos & $28 \%$ & $-23 \%$ & $60 \%$ & $1 \%$ & $28 \%$ & $62 \%$ & $-24 \%$ & $21 \%$ & $19 \%$ \\
\hline beroamericana de & Carreras & $0 \%$ & $13 \%$ & $0 \%$ & $22 \%$ & $0 \%$ & $9 \%$ & $0 \%$ & $0 \%$ & $5 \%$ \\
\hline Ciencias y Tecnología & Títulos & $14 \%$ & $-25 \%$ & $71 \%$ & $-19 \%$ & $187 \%$ & $33 \%$ & $3 \%$ & $3 \%$ & $33 \%$ \\
\hline Internacional Sek & Carreras & $0 \%$ & $0 \%$ & $0 \%$ & $-14 \%$ & $0 \%$ & $0 \%$ & $83 \%$ & $-9 \%$ & $7 \%$ \\
\hline & Títulos & $-35 \%$ & $23 \%$ & $-3 \%$ & $14 \%$ & $14 \%$ & $14 \%$ & $143 \%$ & $-55 \%$ & $14 \%$ \\
\hline La República & Carreras & $0 \%$ & $0 \%$ & $0 \%$ & $18 \%$ & $-23 \%$ & $160 \%$ & $185 \%$ & $7 \%$ & $43 \%$ \\
\hline & Títulos & $14 \%$ & $15 \%$ & $0 \%$ & $7 \%$ & $7 \%$ & $22 \%$ & $33 \%$ & $16 \%$ & $14 \%$ \\
\hline Mariano Egaña & Carreras & $0 \%$ & $0 \%$ & $0 \%$ & $150 \%$ & $-40 \%$ & $167 \%$ & $163 \%$ & $14 \%$ & $57 \%$ \\
\hline & Títulos & $78 \%$ & $26 \%$ & $3 \%$ & $13 \%$ & $14 \%$ & $22 \%$ & $34 \%$ & $42 \%$ & $29 \%$ \\
\hline Mayor & Carreras & $-9 \%$ & $10 \%$ & $18 \%$ & $154 \%$ & $33 \%$ & $30 \%$ & $7 \%$ & $10 \%$ & $32 \%$ \\
\hline & Títulos & $25 \%$ & $1 \%$ & $5 \%$ & $52 \%$ & $34 \%$ & $40 \%$ & $6 \%$ & $9 \%$ & $21 \%$ \\
\hline San Sebastián & Carreras & $0 \%$ & $13 \%$ & $11 \%$ & $0 \%$ & $30 \%$ & $115 \%$ & $111 \%$ & $20 \%$ & $38 \%$ \\
\hline & Títulos & $23 \%$ & $23 \%$ & $-95 \% * 2$. & $073 \% *$ & $22 \%$ & $22 \%$ & $19 \%$ & $78 \%$ & * \\
\hline Santo Tomás & Carreras & $8 \%$ & $0 \%$ & $0 \%$ & $46 \%$ & $-5 \%$ & $0 \%$ & $511 \%$ & $15 \%$ & $72 \%$ \\
\hline & Títulos & $-24 \%$ & $23 \%$ & $3 \%$ & $17 \%$ & $3 \%$ & $2 \%$ & $17 \%$ & $9 \%$ & $6 \%$ \\
\hline
\end{tabular}


$\begin{array}{lllllllllll}\text { Pérez Rosales } & \text { Carreras } & -17 \% & 20 \% & 0 \% & 17 \% & 14 \% & 225 \% & 42 \% & -16 \% & 36 \%\end{array}$

\begin{tabular}{llllllllll} 
Títulos & $0 \%$ & $78 \%$ & $23 \%$ & $10 \%$ & $10 \%$ & $-8 \%$ & $13 \%$ & $16 \%$ & $10 \%$ \\
\hline
\end{tabular}

Se omitieron de esta tabla once instituciones que no presentaron información sobre matrícula, carrera y/o títulos de biblioteca en algunos de los años de este periodo.

Las celdas sombreadas corresponden al año de la certificación de autonomía en cada institución. Si una institución no presenta celda sombreada, se debe a que su autonomía fue certificada con anterioridad al primer año del periodo en análisis.

Se han destacado con un asterisco aquellas cifras que son erróneas y que distorsionan las variaciones y los promedios de las instituciones, por lo que no se consideraron en el análisis.

Tal como se observó en el número de volúmenes de biblioteca de cada institución, la cantidad de títulos disponibles ha evolucionado, en términos generales, de manera bastante errática, apreciándose incrementos poco sistemáticos e, incluso, años de aumento de las colecciones bibliográficas alternados con años de reducción de las mismas. Su relación con la cantidad de carreras tampoco es directa, pues, en efecto, las variaciones anuales del número de títulos de biblioteca en este periodo no se desarrollan de manera armoniosa con la evolución del número de carreras, a excepción de algunos casos en que el aumento de la matrícula es particularmente abrupto y es acompañado con un incremento de títulos superior a los años anteriores.

Los promedios de las variaciones anuales de cada institución sólo muestran que hay un crecimiento generalizado de los títulos de biblioteca, pero no son tan claros al relacionarlos con el número de carreras. La mayoría de las instituciones presentan un incremento de sus títulos de biblioteca menor al del número de carreras y sólo cuatro de ellas muestran un incremento similar.

\subsection{Comportamiento general de los recursos bibliográficos}

En todas las instituciones las colecciones de biblioteca han venido en aumento, en términos del número de volúmenes y de títulos existentes, incluso en aquellos pocos casos en que el crecimiento de matrícula ha sido nulo. Ello se confirma al examinar los promedios de crecimiento entre 1997-2004 que, en todas las instituciones, son positivos. No obstante, un análisis de las variaciones año a año revela 
que el crecimiento de las colecciones de biblioteca no suele ser homogéneo en el tiempo, sino, por el contrario, tiende a ser algo errático y, en muchas ocasiones, sin explicación en el número de alumnos o de carreras en los años correspondientes.

\section{Conclusiones}

1. Principales características de la expansión de las instituciones con autonomía certificada por el Consejo Superior de Educación

Se comprueba un crecimiento del conjunto de instituciones con autonomía certificada por el Consejo Superior de Educación. Sin embargo, no todas las instituciones elevaron su tasa de crecimiento inmediatamente después de la autonomía.

Las universidades e institutos profesionales acreditados por el Consejo Superior de Educación muestran, salvo contadas excepciones, una tendencia de crecimiento en términos de matrícula, carreras, sedes y áreas del conocimiento.

Si bien los ritmos de crecimiento difieren entre instituciones y, en la mayoría de los casos, no es un crecimiento homogéneo a lo largo de los años, el efecto agregado es el aumento significativo de estudiantes, programas de pregrado y sedes entre 1996 y 2004.

En efecto, la matrícula total de este conjunto de instituciones se elevó en dicho periodo desde 60 mil estudiantes a casi 160 mil. La matrícula de primer año pasó de 16 mil a poco más de 56 mil. Del mismo modo, el número de sedes era de 41 en 1996 y de 135 en 2004. La cantidad de carreras que estas instituciones ofrecen ha pasado desde 268, a inicios del periodo, a más de 2 mil a finales de éste. El número de áreas del conocimiento que, en promedio, estas instituciones cubren con sus programas académicos era de 4 áreas en 1996 y de 6,4 el 2004. 
El análisis por instituciones reveló que tampoco es tan evidente el crecimiento drástico inmediatamente después de la autonomía o, al menos, no es en absoluto una reacción automática para cualquier institución. En efecto, fue posible observar algunos casos en que la matrícula creció, el año posterior a la autonomía, a una tasa cercana a la de los años anteriores a ella. Por lo menos cinco institutos profesionales y seis universidades del grupo analizado no mostraron, inmediatamente después de la autonomía, crecimientos superiores a los de los años previos.

El crecimiento de estas instituciones ha sido particularmente drástico a partir de esta década.

El aumento descrito se acelera en todos los indicadores mencionados -matrícula, carreras, sedes y áreas del conocimientodesde principios de esta década en adelante y se desacelera en el año 2004, también en todos los indicadores.

Efectivamente, la matrícula de primer año de las instituciones experimenta sus máximas variaciones anuales en los años 2000 (27\%), 2002 (32\%) y 2003 (28\%), y la matrícula total muestra sus variaciones más altas en los mismos años con variaciones de 16 , 17 y $23 \%$, respectivamente.

El número de sedes y de carreras también aumenta con particular fuerza en 2003, alcanzando variaciones elevadísimas de 79 y $71 \%$, respectivamente. El promedio del número de áreas del conocimiento que las instituciones desarrollan es especialmente alto en 2002 y 2003, con variaciones anuales de 13 y 15\%.

Los indicadores que muestran un incremento más agudo son aquellos relativos a la oferta educacional.

El crecimiento agregado de estas instituciones se caracteriza por ser particularmente agudo en dos indicadores: número de sedes y número de carreras. 
En efecto, en los últimos años la cantidad de sedes y de carreras ha crecido, en general, en proporciones superiores a la evolución de la matrícula, alcanzando en 2003 tasas por encima del $70 \%$. En ese sentido, las variables que responden fundamentalmente a la oferta educacional muestran las cifras más elevadas, quedando bastante lejos de los máximos del crecimiento de la matrícula, que es un indicador asociado preferentemente a la demanda.

Ello sugiere que no se llenan siempre las vacantes de los programas académicos ofrecidos y que podría haber una falta de información en los fundamentos de mercado que sustentan las decisiones institucionales de ampliación de su oferta.

El crecimiento de este grupo de instituciones y la agudización de este crecimiento en los últimos años se explican por la interacción de dos fuerzas: la expansión de las instituciones más antiguas y la condición de autonomía de las más jóvenes.

Una de las características del crecimiento de este conjunto de instituciones es que se aceleraba desde inicios de la presente década en todos los indicadores utilizados. Al revisar las cifras de expansión inmediatamente después de la certificación de la autonomía y, posteriormente, las cifras de instituciones que ya eran autónomas hace algunos años, se identificó la existencia de dos fuerzas que explicaban el brusco aumento en la tasa de crecimiento.

En primer lugar, hay algunas instituciones con menos años de funcionamiento y cuya autonomía fue certificada recientemente, que muestran, en el año posterior a dicha certificación, una expansión de su oferta bastante mayor al crecimiento histórico. Ello se asocia probablemente a las condiciones a que están sujetas las instituciones durante los años de verificación del CSE previos a la autonomía. En ese lapso, las instituciones deben someter a consideración de este Consejo todos los proyectos de nuevas sedes y de nuevas carreras, lo 
que evidentemente implica ciertos costos financieros y de tiempo y limita su margen de gestión, su capacidad de adaptación y su velocidad de crecimiento. Posteriormente, las instituciones, una vez que se certifica su autonomía y quedan liberadas de la supervisión del Consejo, pueden tomar decisiones de desarrollo sin la regulación de un ente externo, lo que las motiva a incursionar en nuevas líneas de desarrollo, ya sea en más carreras, en nuevas sedes e, incluso, en programas académicos correspondientes a otras áreas del conocimiento.

Una segunda fuerza que opera fuertemente en los últimos años es la expansión de instituciones con más años de funcionamiento y de autonomía certificada con anterioridad a esta década, que muestran un punto de inflexión en su crecimiento varios años después de la certificación de su autonomía. Este punto de inflexión se localiza mayoritariamente en los primeros años de la presente década, agudizando la tendencia agregada de crecimiento. A diferencia del grupo anterior, estas instituciones han crecido en virtud de una opción de desarrollo que se asocia a razones de mercado y no a una condición interna como es estar o no sujetas a la regulación de otro organismo.

Eso no quiere decir que estas dos fuerzas hayan funcionado de manera independiente o que sean excluyentes. Por el contrario, probablemente su acción ha sido complementaria, es decir, la decisión de ampliar la oferta inmediatamente después de la autonomía es una opción fuertemente asociada a razones de mercado, a elevar la competitividad y a asegurar la sobrevivencia, entre otras. A su vez, las instituciones que ya son autónomas desde la década pasada, se han visto en la necesidad de expandirse dentro de un escenario que se ha modificado sustancialmente en virtud de una gran cantidad de autonomías institucionales que se han certificado y que han permitido un crecimiento inédito de las instituciones más jóvenes.

El crecimiento de varias de estas instituciones ha pasado de ser intensivo a ser extensivo. 
Al cruzar la información disponible sobre crecimiento de la matrícula, aumento de carreras, apertura de sedes y desarrollo de nuevas áreas del conocimiento, es posible suponer que se ha dado un fenómeno de crecimiento intensivo, primero, y de crecimiento extensivo, después.

Es decir, mientras estas instituciones se encuentran en el proceso de verificación con el CSE se focalizan en aumentar su matrícula en las carreras que ya imparten, dado que la oferta de vacantes es una variable que pueden controlar sin necesidad de regulación externa, mientras que las carreras y sedes es una decisión que para implementarse debe ser aprobada por el Consejo. Esto resulta en un crecimiento intensivo de varias instituciones, es decir, una evolución caracterizada por el incremento de la matrícula, pero sin mostrar un aumento significativo de sus programas académicos o de sedes.

Una vez que las instituciones obtienen la condición de autonomía, se ven posibilitadas de iniciar una estrategia de desarrollo diferente, donde sus esfuerzos apuntan a mantener niveles razonables de matrícula en sus carreras históricas y a extenderse hacia nuevas carreras, nuevas sedes e, incluso, hacia nuevas áreas del conocimiento. Se da, entonces, un desarrollo principalmente extensivo.

El crecimiento de este grupo de instituciones se desacelera notoriamente en 2004.

Las variaciones anuales de todos los indicadores señalados -matrícula, carreras, sedes y áreas de conocimiento- descienden considerablemente en 2004, quedando entre 5 y $16 \%$ de crecimiento.

Aunque es pronto para afirmarlo con seguridad, estas cifras podrían ser una señal de una incipiente estabilización del sistema, donde las nuevas tendencias de desarrollo serán con tasas de 
crecimiento bastante más bajas que las observadas en los últimos años.

También podría deberse a un agotamiento de la demanda por estudios de tipo tradicional, que forzaría a las instituciones a entrar en una nueva etapa de desarrollo extensivo, caracterizado por la aparición de una oferta no tradicional, como programas académicos de menor duración, programas de educación online, entre otros.

2. La evolución de los indicadores involucrados en el proceso de enseñanza en las instituciones con autonomía certificada por el Consejo Superior de Educación

El desarrollo de los indicadores docentes y bibliográficos que han sido analizados es creciente en todo el periodo y en todas las instituciones.

En efecto, el número de profesores ha aumentado como tendencia, aunque no siempre de manera proporcional con la matrícula o la cantidad de carreras. No obstante esto último, fue posible constatar un aumento significativo de docentes en todas las ocasiones en que hubo incrementos drásticos de matrícula.

Asimismo, los títulos y volúmenes de biblioteca han venido en aumento en todas las instituciones, aunque es posible identificar en la mayoría de ellas un desarrollo algo irregular en la dotación de tales recursos.

Aun cuando el número de docentes ha aumentado en las instituciones, las condiciones de su dedicación horaria así como su nivel de calificación no se han modificado mayormente entre 2000-2004.

En este conjunto de instituciones, la proporción de profesores de jornada media o mayor se mantiene, en promedio, entre 21 y $26 \%$ en el lustro analizado. Llama la atención la evolución de esta 
variable, ya que se aprecia un aumento entre los años 2000 y 2002 que lleva la cifra desde 22 hasta $26 \%$ y, luego, un descenso que en 2004 se traduce en un $21 \%$. De ese modo, la situación prácticamente no habría variado desde principios del periodo examinado.

El análisis por instituciones arrojó que hay diferencias significativas entre ellas respecto del porcentaje de profesores de jornada con que funcionan. En efecto, las proporciones van desde un promedio de 6\% que presenta el Instituto Profesional ARCOS hasta el promedio de $42 \%$ que mantiene el Instituto Profesional EATRI. Aun cuando el porcentaje extremo inferior y el superior se localizan entre los institutos profesionales, cabe notar la diferencia esperable entre los promedios de éstos y los de las universidades, pues estas últimas suelen mostrar plantas académicas con una dotación más alta de profesores contratados por jornada. Entre las universidades, la proporción más alta de profesores de jornada, en promedio, la tienen las universidades Católica Silva Henríquez, Alberto Hurtado y Del Mar, con 36, 35 y 34\% respectivamente, mientras que el porcentaje más bajo lo muestra la Universidad Finis Terrae con un $10 \%$ de profesores de jornada. Por otra parte, llama la atención que, en varios casos, una misma institución presenta cifras altamente variables de año en año, resultando una evolución de su cuerpo académico bastante irregular a lo largo del periodo en materia de dedicación horaria.

En cuanto al nivel de calificación de los docentes, el porcentaje con formación de posgrado aumenta levemente en estas instituciones, pasando de $24 \%$ en 2000 a 27\% en 2004. Aquí también hay que considerar las diferencias que pueden esperarse entre las universidades y los institutos profesionales, en términos del nivel de calificación de sus académicos. Entre los últimos, el porcentaje de profesores con posgrado va desde un promedio de $4 \%$ en el Instituto Profesional ARCOS hasta un 18\% en el Instituto Profesional La Araucana. En el caso de las universidades, las menores proporciones en promedio de profesores con estudios de posgrado las tienen las universidades de Viña del Mar y La República 
con 18\%, y la mayor proporción la presenta la Universidad Alberto Hurtado con un $72 \%$.

En cuanto a la evolución de los cuadros académicos en el tiempo, cabe destacar las diferencias en cada caso, pues hay un grupo de instituciones considerable que mantiene constante su proporción de profesores con posgrado, algunas que presentan crecimientos de este índice y un conjunto no menor de ellas que ha experimentado una evolución bastante errática.

Esta situación de irregularidad a lo largo de los años, en indicadores tan relevantes como la dedicación de sus docentes o su nivel de formación, levanta inquietudes acerca de la definición de políticas de desarrollo de los cuerpos académicos, sobre los sistemas de selección y perfeccionamiento, como, asimismo, los mecanismos de rotación y de permanencia.

Los recursos bibliográficos disponibles en las instituciones muestran tendencias de aumento entre 1996-2004, pero su contrastación con la matrícula y el número de carreras no arroja una evolución siempre armónica con éstas.

Al observar las cifras de cantidad de títulos y volúmenes disponibles, éstas son crecientes en el tiempo y sus promedios de incremento no están lejos de los promedios de crecimiento del número de alumnos y de la cantidad de carreras ofrecidas. Pero el análisis de su evolución año a año arroja que el crecimiento de las colecciones de biblioteca no suele ser homogéneo en el tiempo, sino, por el contrario, tiende a ser algo errático y, en muchas ocasiones, sin explicación en el número de alumnos o de carreras en los años correspondientes.

Hay una alta variabilidad de estos indicadores, tanto a lo largo de los años como entre las instituciones, lo que hace prácticamente imposible identificar tendencias. 
Las cifras relativas a recursos docentes y bibliográficos de este grupo de instituciones se caracterizaron por mostrar una alta variabilidad que hizo difícil poder identificar tendencias.

En primer lugar, se observaron situaciones muy diferentes entre instituciones en términos del crecimiento de sus cuerpos académicos, de la proporción de profesores de jornada y del porcentaje de académicos con formación de posgrado. Lo mismo se pudo constatar al analizar el desarrollo de las colecciones de biblioteca de estas instituciones.

En segundo término, se pudo apreciar una alta irregularidad de todos estos indicadores dentro de una misma institución, es decir, evoluciones bastante erráticas de año en año, que hacían que, en muchos casos, los promedios de los periodos perdieran su poder descriptivo, en la medida que los extremos los distorsionaban. Esta irregularidad fue particularmente notoria en las cifras relativas a la cantidad de títulos y de volúmenes de biblioteca con que cuentan las instituciones.

Es particularmente llamativa la irregularidad en los recursos bibliográficos, donde la tendencia debiera ser de aumento de las colecciones de biblioteca o, a lo menos, de mantención de ellas. No se comprende, en este sentido, que las colecciones decrezcan significativamente de un año al siguiente. Este hecho nos enfrenta a dos preguntas. La primera es por la definición de políticas de desarrollo de las instituciones y por el establecimiento de estándares o criterios de funcionamiento y de disponibilidad de recursos. En definitiva, es la pregunta por una planificación que se traduzca en evoluciones de las cifras más regulares en el tiempo y coherentes entre unos indicadores de desarrollo y otros. La segunda interrogante es relativa a la precisión de la información que las instituciones registran y difunden sobre sus propios indicadores de gestión, ya que el análisis de la información realizado institución por institución y año a año arrojó, en ocasiones, datos que son inexplicables o que no tienen sentido en su contexto, por lo que es 
altamente probable que haya una cuota importante de errores en la información aportada por las instituciones.

Es probable que estos dos aspectos cuestionados, lejos de ser situaciones excluyentes, sean fundamentalmente complementarias, es decir, que ambos aspectos estén siendo deficitarios en las instituciones de educación superior, por lo que será importante relevar estos temas y avanzar en ambos sentidos: la planificación para el desarrollo gradual y armonioso de las instituciones en sus distintas áreas y la validez y completitud de la información entregada por ellas.

Nota: Las cifras que sirvieron de base a las conclusiones de este informe, están incorporadas en el sitio en internet del CSE: http://www.cse.cl 